\author{
Gerd-Helge Vogel
}

\title{
AUGUST MATTHIAS HAGEN (1794-1878) - DEUTSCHBALTISCHE LANDSCHAFTSMALEREI ZWISCHEN ROMANTISCHEM AUFBRUCH UND PROVINZIELLER SELBSTGENÜGSAMKEIT
}

\author{
HAGENS SPIRITUELLE BEGEGNUNG \\ MIT CASPAR DAVID FRIEDRICH
}

Außerhalb des Baltikums und Russlands hat August Matthias Hagen, der ehemalige Zeichenmeister der Universität Dorpat, erst in jüngster Vergangenheit auch die Aufmerksamkeit des europäischen Kunstpublikums erregt. Der Grund dafür liegt in der augenscheinlichen Affinität manch seiner Werke mit jenen von Caspar David Friedrich (1774-1840), auf die im Jahre 2006 Jens Christian Jensen in seinem Beitrag zum Katalog Caspar David Friedrich und Umkreis in der Galerie Hans in Hamburg erstmals hinwies. ${ }^{1} 2008$ ergänzten Boris Asvarishch und Henk van Os diese Beobachtungen in ihren Katalogessays zur Ausstellung Caspar David Friedrich \& the German Romantic Landscape in der Hermitage Amsterdam², die zwei der Werke Hagens aus der Sammlung der Petersburger Eremitage in den Niederlanden präsentierte: "The paintings by Hagen in the Hermitage are both done with extraordinary

DOI: http://dx.doi.org/10.12697/BJAH.2015.10.02

1 Vgl. Jens Christian Jensen, "Einwirkungen Caspar David Friedrichs auf August Matthias Hagen. Die Insel Suursaari im Werk des baltischen Malers", Caspar David Friedrich und Umkreis, bearb. Christine Szkiet u. a. (Hamburg: Galerie Hans, 2006), 98-103.

2 Vgl. Boris I. Asvarishch, "Caspar David Friedrich in Russia”, Caspar David Friedrich \& the German Romantic Landscape, ed. by Hermitage Amsterdam (Aldershot: Lund Humphries, 2008), 72-73; Henk van Os, "Caspar David Friedrich and his contemporaries", Caspar David Friedrich \& the German Romantic Landscape, 30-31, 34-35. 


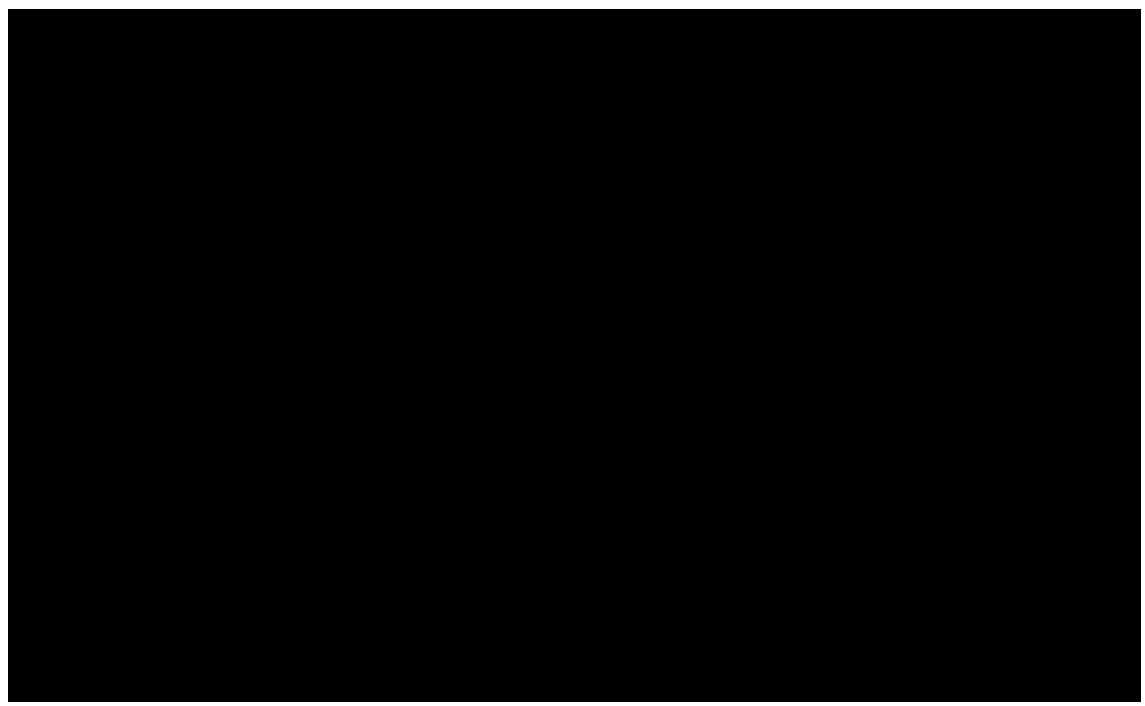

Abb. 1. August Matthias Hagen, Berge, Ölgemälde, 1835. Ermitage.

precision and a fine sense of the effect of light and sky in the landscape. But the most striking is the role of the human figures. The figure seen from the back in the inhospitable mountain landscape has literally and figuratively reached the end of his road. Nature has become too much for him. In the seascape the two figures on the rock are so minuscule that all they can do now is indicate the overwhelming grandeur of nature. The human scale serves only to reinforce the immensity of the vista. Although the function of these figures is different with Friedrich, it must surely have been paintings by him that persuaded Hagen to use these theatrical effects with silhouettes of human figures." ${ }^{3}$ In der Tat stellen die beiden 1835 gemalten Bilder Berge (Abb. 1) und Meeresbucht (Abb. 2), die Hagen zusammen mit weiteren 27 Werken auf Vermittlung seines Kommilitonen und Freundes Wassilij Andrejewitsch Schukowskij (auch: Shukovski/Shukovskij/Zhukovsky/Joukovsky, 1783-1852) in den Jahren 1834/35 im Auftrag des russischen Unterrichtsministers und Präsidenten der Akademie der Wissenschaften Sergej S. Uvarow (1786-1855) "für den kaiserlichen Hof in St. Petersburg"4 malte, nicht

3 Van Os, "Caspar David Friedrich and his contemporaries", 30.

4 Günter Krüger, Die Zeichenschule der Universität Dorpat 1803-1891. Teil II: Unter der Leitung von August Matthias Hagen und Woldemar Friedrich Krüger (Husum: Husum Druck- und Verlagsges., 1995), 12. 


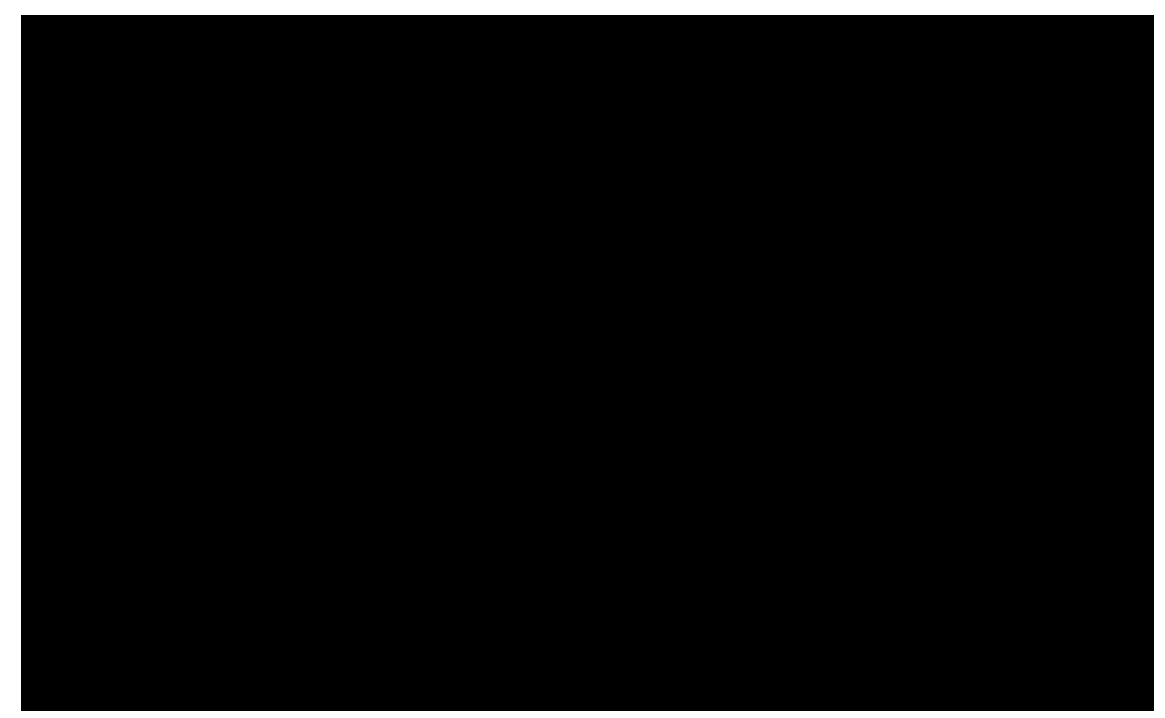

Abb. 2. August Matthias Hagen, Meeresbucht, Ölgemälde, 1835. Ermitage.

nur einen Höhepunkt in der Friedrich-Rezeption im Russischen Reich dar, sondern zugleich den Kulminationspunkt von Hagens künstlerischem Gesamtschaffen überhaupt. Eine ganze Reihe von im Juni und Juli 1835 datierten Zeichnungen mit Ansichten von Südfinnland ${ }^{5}$ und von den im Finnischen Meerbusen gelegenen Inseln - die, wie vor allem die Insel Hogland (oder Hochland), erst 1809 im Finnischen Krieg an das Russische Reich verloren gingen und mit Unterbrechung von 1920 bis 1947 bis heute dort verblieben sind ${ }^{6}$ - gehören zum Portefeuille ${ }^{7}$, das von diesem Auftrag erhalten ist, während der Großteil der nach diesen Zeichnungen entstandenen Gemälde inzwischen verschollen ist. ${ }^{8}$ Nachdem Hagen 1833 auf der Petersburger Akademie-Ausstellung zwei

5 Vgl. August Matthias Krüger, Die Stadt Tavastehus (finnisch Hämeenlinna), 7. Juli 1835, Sepia 283x422 mm, Privatbesitz (s. Krüger, Die Zeichenschule der Universität Dorpat 1803-1891, 29 ohne Abb.).

6 Die nunmehr russische Insel Gogland (finnisch Suursaari, estnisch Suursaar und schwedisch Hogland) wurde seit dem 16. Jahrhundert von Finnen besiedelt und erlebte an ihren Küsten mehrere Seeschlachten (z. B. am 22. Juli 1713 im Großen Nordischen Krieg oder im Russisch-Schwedischen Krieg die Schlacht von Hogland).

7 Z. B. August Matthias Hagen, Ansicht von Suursaar (Insel Hochland, Hogland), 1835, Sepia, Lehrstuhl für Geologie der Universität Tartu (s. Voldemar Vaga, Kunst Tartus XIX sajandil (Tallinn: Kunst, 1971), Abb. 65), (Ansicht von Hogland, 1835, Sepia, dort: Unibibl. Tartu (Abb. 3 Jensen)); August Matthias Hagen, Felsen auf der Insel Hochland mit Wanderer, 23. Juni 1836, Sepia 275x422 mm, Privatbesitz (s. Krüger, Die Zeichenschule der Universität Dorpat 1803-1891, 29 ohne Abb.).

8 Vgl. Vaga, Kunst Tartus XIX sajandil, 125. 
Bilder präsentiert hatte, wurden im Dezember 1834 vom Zarenhof sechs Landschaften mit Ansichten von Livland für 3.500 Rubel vom Künstler erworben, dem kurz darauf 25 weitere Landschaftsbilder folgten. ${ }^{9}$ Seine Kunst gefiel am kaiserlichen Hof und so kam es zum neuerlichen Auftrag; nunmehr mit Ansichten von Landschaften der dem Zarenreich neu hinzugewonnenen finnischen Gebiete. Zu diesem Zweck musste Hagen nach Petersburg und Finnland reisen, sodass er vorübergehend von seinem seit 1826 am Gouvernements-Gymnasium in Dorpat ausgeübten Amt als Zeichenlehrer beurlaubt werden musste, wo ihn in der Zwischenzeit Hermann Eduard Hartmann (1817-1880), sein Schüler, vertrat. ${ }^{10}$

\section{HAGEN UND DIE THEORIE DER ROMANTISCHEN LANDSCHAFTSKUNST - SEINE BESCHÄFTIGUNG MIT CARL GUSTAV CARUS' “ZEHN BRIEFE ÜBER LANDSCHAFTSMALEREI"}

Auffällig ist Hagens großes Interesse an den geologischen Strukturen der Felsformationen, die er auf den Klippen der südfinnischen Inseln vorfindet. Drei Beispiele dafür sind die Sepien, die er im Juni 1835 von einer Porphyrwand auf Hogland (Abb. 3), einer Ansicht von Hogland ${ }^{11}$ und von einer Schlucht auf der Insel Hochland ${ }^{12}$ - vermutlich als Vorarbeiten zu Gemälden - fertigte, und die die Kenntnis der Briefe über Landschaftsmalerei widerzuspiegeln scheinen, die Carl Gustav Carus zwischen 1815 und 1826 verfasste und 1835 bereits in einer zweiten Auflage herausgab. ${ }^{13}$ Carus formulierte in dieser kunstheoretischen Schrift die Idee vom romantischen Erdlebenbild oder der geognostischen Landschaft und forderte, dass der Künstler "die Sprache der Natur /---/ reden lernen [solle], und der Hörsaal, wo ein solcher Unterricht von ihm empfan-

9 Vgl. Asvarishch, German and Austrian Painting. Nineteenth and Twentieth Centuries (Firenze: Giunti Gruppo Editoriale, 1988), 114.

10 Vgl. Krüger, Die Zeichenschule der Universität Dorpat 1803-1891, 12.

11 August Matthias Hagen, Ansicht von Hogland, 1835, Sepia, Universitätsbibliothek Tartu, vgl. Jensen, "Einwirkungen Caspar David Friedrichs auf August Matthias Hagen. Die Insel Suursaari im Werk des baltischen Malers", 100-101, Abb.3.

12 August Matthias Hagen, Eine Schlucht im Gebirge auf der Insel Hochland, 20. Juni 1835, Sepia. $441 \times 347$ mm, Universitätsbibliothek Tartu, ÜR 4695. Vgl. "August Mattias Hagen”, Парашутовi (02.10.2013), http://www.liveinternet.ru/users/2010239/post293779207/, vgl. "Julie Wilhelmine Emilie Hagen-Schwarz", Парамутові (02.10.2013), http://www.liveinternet.ru/users/2010239/rubric/1674236/ (zuletzt aufgerufen 12.11.2015).

13 Vgl. Carl Gustav Carus: Briefe und Aufsätze über Landschaftsmalerei, hrsg. Gertrud Heider (Leipzig, Weimar: Gustav Kiepenheuer Verlag, 1982), 189-190. 


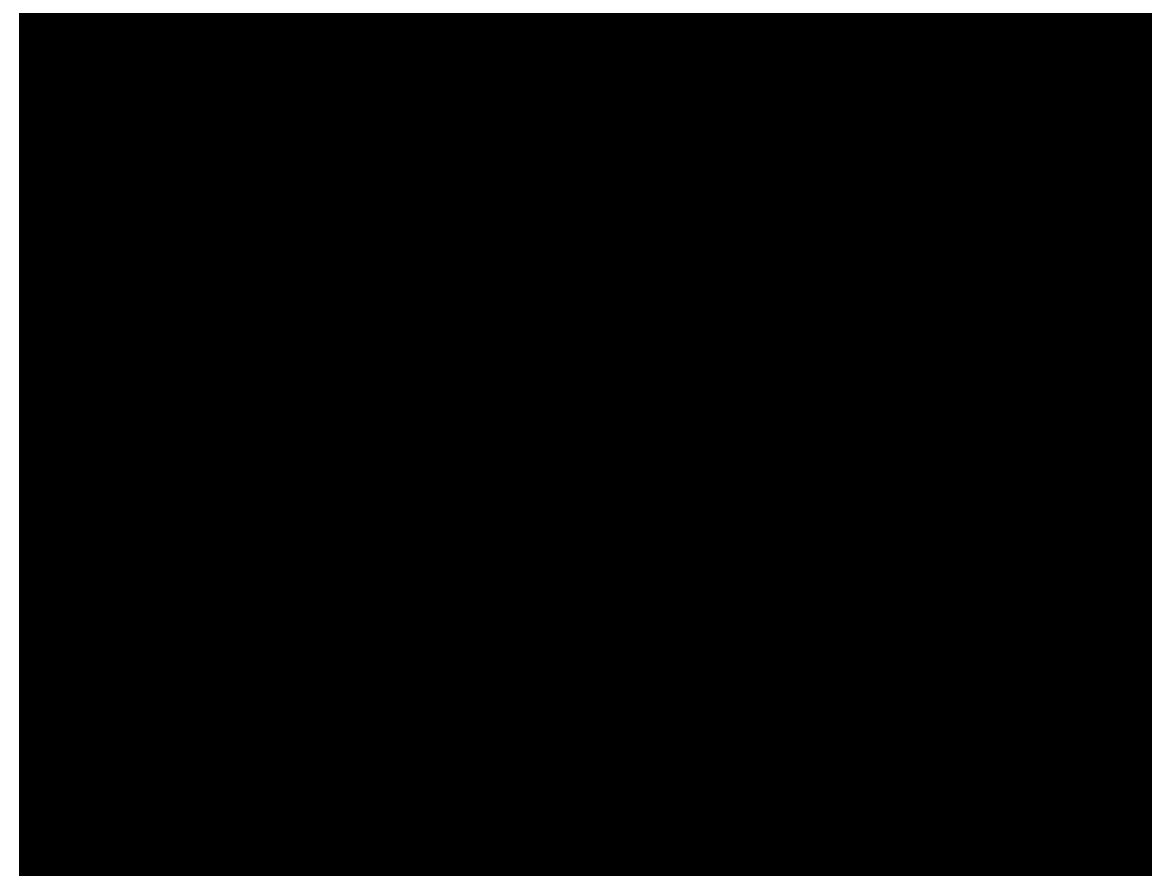

Abb. 3. August Matthias Hagen, Porphyrwand auf Hogland, Sepiazeichnung, 1835. Privatbesitz.

gen werden kann, /---/ nur die freie Natur selbst [sei]"..14 Entsprechend stand die Gestaltung der Naturprozesse, das ewige Werden, Wachsen und Vergehen, die Erosion durch Wind und Wetter und der Kampf der Vegetation, das lebensabweisende Felsgestein zu besiedeln, im Vordergrund. Damit schwebte Carus eine neue Landschaftskunst vor, die in der "Erdlebenbildkunst ... die in ihr verborgene göttliche Idee richtig [erfasst]"15 und in poetischer Weise zum Ausdruck bringt. Doch wie war Hagen zur Kenntnis dieser theoretischen Überlegungen von Carus romantischer Landschaftsauffassung gelangt? Wir wissen es nicht, doch ist die Wahrscheinlichkeit groß, dass dies über seinen Freund, den Dichter und Künstler, den Prinzenerzieher und Staatsrat Wassilij Andrejewitsch Schukowskij (1783-1852) erfolgte, der bereits 1815 nach Dorpat kam, wo er sich mit Hagen anfreundete, der bis 1817 gelegent-

14 Carl Gustav Carus, VIII. Brief über Landschaftsmalerei (1826), in: Carl Gustav Carus: Briefe und Aufsätze über Landschaftsmalerei, 88.

15 Carl Gustav Carus, VII. Brief über Landschaftsmalerei (1826), in: Carl Gustav Carus: Briefe und Aufsätze über Landschaftsmalerei, 68. 
lich sein Mitschüler im Unterricht des Universitätszeichenmeisters Carl August Senff (1770-1838) war. Als sich Schukowskij später in Dresden mit der sächsischen Kunstszene bekannt machte, gehörte dort Carl Gustav Carus (1789-1869) neben Caspar David Friedrich mit zu seinen engsten Vertrauten. Carus erinnerte sich: "Eine andere Begegnung ferner, welche wieder für meine künstlerische Tätigkeit nicht ohne Folgen blieb, war die mit dem russischen Staatsrat Joukowsky, dessen Bekanntschaft schon vor mehrern Monaten ich in einer Petersburger Familie gemacht hatte, welche zu meiner ärztlichen Klientel gehörte. Herr von Joukovsky, in Rußland als Gelehrter und Dichter, insbesondere auch als Übersetzer Schillers bekannt, war von Kaiser Nikolaus zum Erzieher des jungen Kronprinzen Alexander bestimmt, und durch das Gemütvolle seines Wesens und seine vielseitige Bildung hatte hier alsbald eine nähere Berührung zwischen uns sich ebenfalls ergeben. Er besuchte mich darauf, sah meine Bilder, und vorzüglich eins, wo die drei Könige aus Morgenland in frühem Tagesgrauen dem geheimnisvollen Sterne nachziehen, es wirkte so nachhaltig, daß er mich ersuchte, ihm ein ähnliches zu malen /---/."16 Carus hatte zum Zeitpunkt des Treffens seine Briefe über Landschaftsmalerei gerade vollendet und damit ist es wohl mehr als naheliegend, dass diese kunsttheoretischen Überlegungen über Landschaftsmalerei auch Gegenstand ihrer Diskussionen waren, zumal der russische Dichter der Romantik selbst ganz ähnliche Auffassungen vertrat, denn auch Schukowskij betrachtete "die Natur [als] ein lebendiges Buch. Als Dichter, als Zeichner und als denkender Mystiker las er in diesem Buche drei verschiedene Texte. Die Hauptsache der Naturbetrachtung bestand für ihn nicht in dem äußern Sinnenreiz, sondern in der Begegnung mit dem verborgenen Leben der Weltseele in ihren Regungen und Bewegungen, in ihrem stummen Leid und ihrer Sehnsucht nach Wiedervereinigung mit dem Himmel. Der mystische Zusammenklang zwischen der menschlichen Seele und der Seele der Natur war für den Sänger des Ewig-Seelischen das Grundmotiv aller Beobachtungen der schönen, erhabenen und furchtbaren Antlitze der einen Weltseele. /---/ Er suchte in der irdischen Schönheit den Abglanz des Himmlischen und sah in allen äußeren Hüllen der sichtbaren Natur

16 Carl Gustav Carus, Lebenserinnerungen und Denkwürdigkeiten, Bd. I, hrsg. Elmar Jansen (Weimar: Gustav Kiepenheuer Verlag, 1966), 476-477. Ergänzend siehe auch S. 428 und Bd. II, S. 131, die ein Licht auf das enge geistige Band, das zwischen Carus und Joukovsky/Shukowski während dessen Dresdenaufenthaltes 1827 bestand, werfen. 


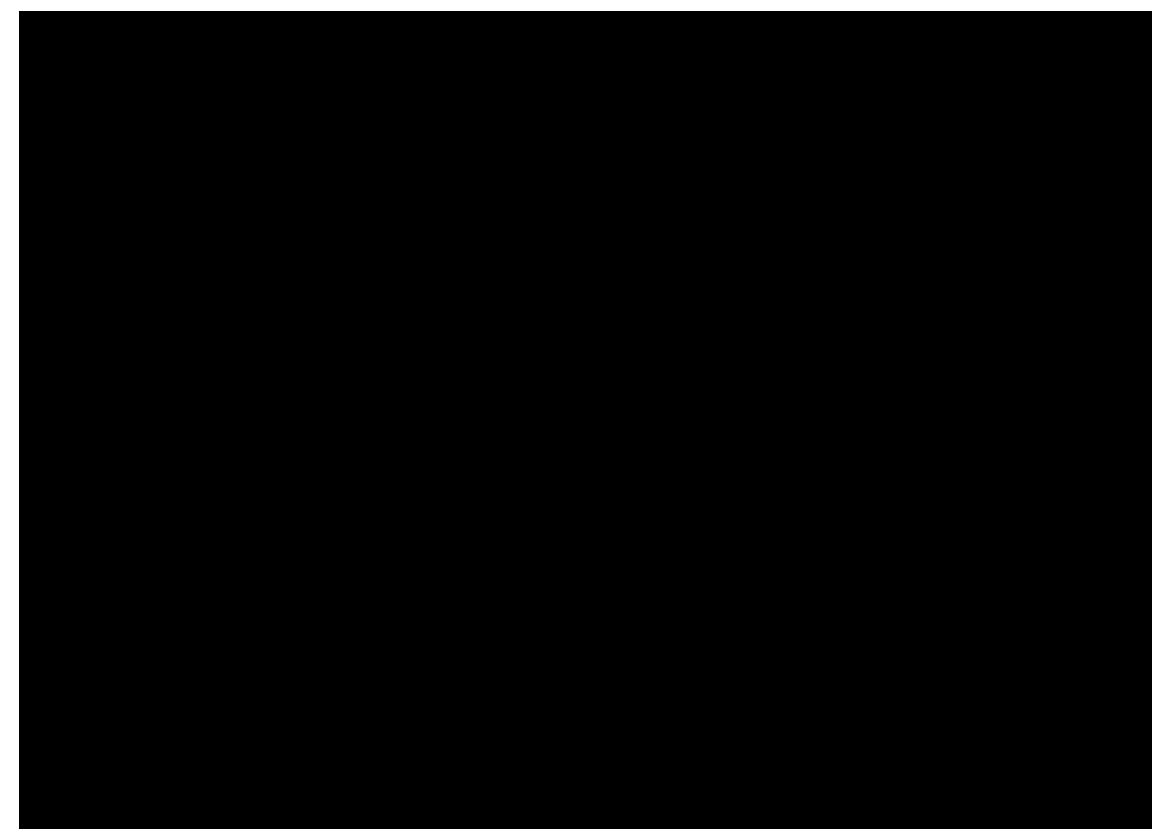

Abb. 4. August Matthias Hagen, Friedhof bei Nacht, Ölgemälde. Privatbesitz.

die Sinnbilder ihres Lebens und ihrer unendlich langen Geschichte. Die Natur war für ihn zugleich der dauernde Schoß der vergänglichen Ereignisse der menschlichen Weltgeschichte" ${ }^{\prime \prime 17}$, mithin ein Erdlebenbild! Diese Kenntnis und dieses Empfinden einer "mystisch-romantischen Naturauffassung"18 scheint Schukowskij dann an Hagen eventuell in Verbindung mit dem Auftrag für die Bilder des Kaisers weiter vermittelt zu haben, so dass sich hieraus einerseits dessen besonderes Gespür für die geologischen Besonderheiten erklärt, andererseits aber auch die elegischen Stimmungen transzendenten Sehnens, die uns in manchen seiner Darstellungen von Finnland begegnen.

Starker Carus-Einfluss wird beispielsweise in Hagens Gemälde Friedhof bei Nacht (Abb. 4) spürbar, das mindestens mit einer Detailzeichnung vorbereitet wurde (Abb. 5), wo uns sowohl die Art und Weise der Inszenierung der Landschaft als auch deren ikonographische Motive an verschiedene Gemälde des sächsischen Vorbildes erinnern. So weist der

17 Leo Kobilinski-Ellis, "Das goldene Zeitalter russischer Poesie”, W. A. Joukowski. Seine Persönlichkeit, sein Leben und sein Werk (Paderborn: Ferdinand Schöningh, 1933), 169.

18 Ibidem, 195. 


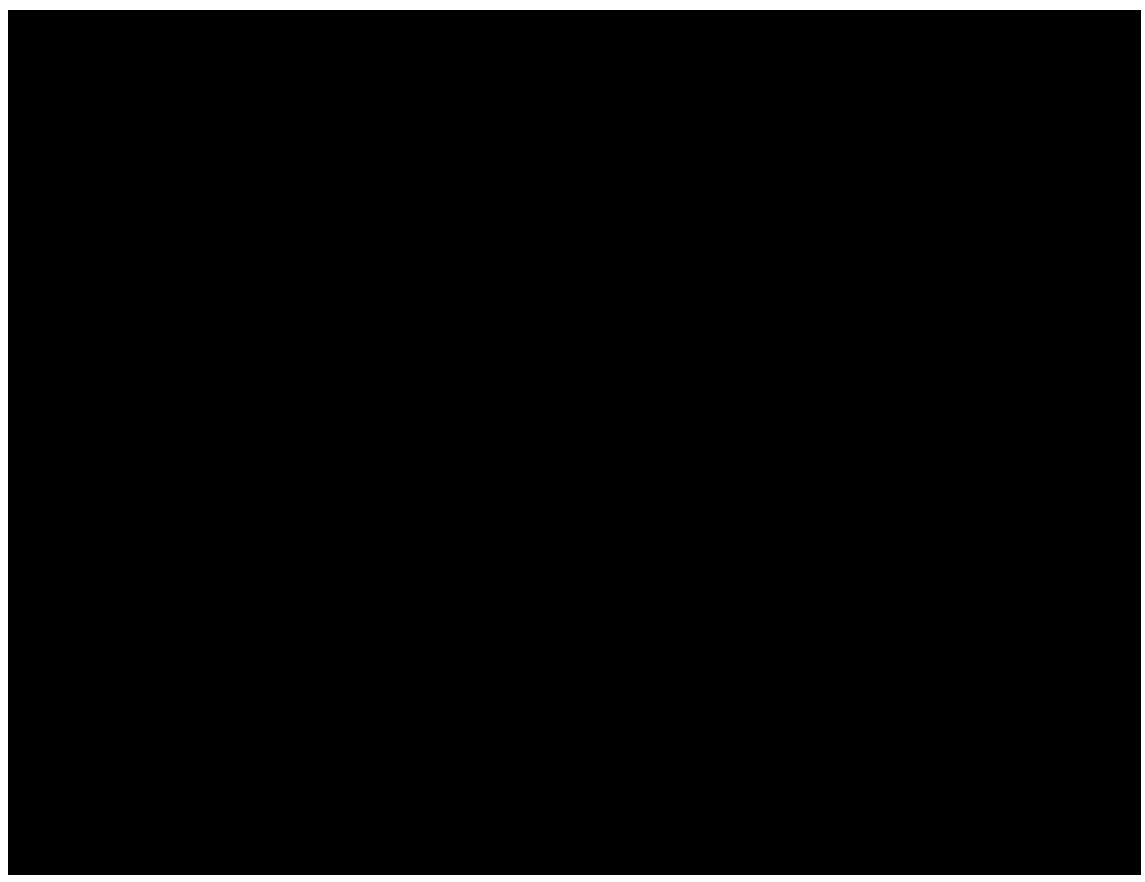

Abb. 5. August Matthias Hagen, Grabkreuze, Sepiazeichnung. Privatbesitz.

bühnenartige Aufbau mit der kulissenhaften Schichtung der Bildgründe gestalterische Parallelen zu Carus Erinnerung an eine bewaldete Insel der Ostsee (Eichen am Meer) ${ }^{19}$ von 1834/35 auf, wo der Blick des Betrachters - gerahmt durch alte, z. T. abgestorbene Eichen - aufs Meer oder auf einen See gelenkt wird, während der als Reich des Todes zu verstehende Vordergrund eines alten Friedhofs mit den umgefallenen Steinkreuzen in Hagens Komposition sowohl die vorgeschichtlichen Steinsetzungen in Carus' Gemälde Erinnerung an Rügen und die Insel Vilm als mehr noch die Motivwelt von Carus Friedhof auf dem Oybin ${ }^{20}$ wachrufen. Hagen zeigt uns in seinem romantischen Mondscheinbild eine nord-

19 Carl Gustav Carus, Erinnerung an eine bewaldete Insel in der Ostsee (Eichen am Meer), 1834/35. Öl/Lw., 117,5x162,5 cm, Galerie Neue Meister, Staatliche Kunstsammlungen Dresden, Gal.-Nr. 2905, vgl. Carl Gustav Carus. Natur und Idee, Katalog zur Ausstellung der Staatlichen Kunstsammlungen Dresden im Semperbau am Zwinger und im Residenzschloss (26. Juni bis 20. September 2009), hrsg. Petra Kuhlmann-Hodick, Gerd Spitzer, Bernhard Maaz (Berlin, München: Deutscher Kunstverlag, 2009), 46, 67-69, Kat. Nr. 52.

20 Carl Gustav Carus, Friedhof auf dem Oybin, 1828, Öl/Lw., 67,5x52 cm, Museum der bildenden Künste Leipzig, Inv.-Nr. 1099, vgl. Carl Gustav Carus. Natur und Idee, 138-140. 
europäische Variante eines Gottesackers, der neben den zahlreichen Steinsetzungen des lateinischen Passionskreuzes Christi auch vierspeichige Radkreuze der altgermanischen Tradition mit einschließt, die als Licht- und Sonnensymbole bzw. als Symbole des Jahres- und Lebenslaufes verstanden wurden und die später als Grundlage des päpstlichen Kreuzes dienten. ${ }^{21}$ Damit klingt ein ökumenischer Gedanke an, der im Tod alle Kulturen vereint. Sowohl in Carus' Bildern als auch in Hagens Komposition zeigt sich eine geistige wie gestalterische Nähe zum Werk Caspar David Friedrichs, das Schukowskij nach Dorpat und St. Petersburg direkt durch sein Wirken als Kunstagent mit dem Erwerb von Friedrichs und Carus' Werken für den Zarenhof ${ }^{22}$ und indirekt durch den von ihm belebten Diskurs vermittelt hatte. Hagen kam in Dorpat bei dem Chirurgen Johann Christian Moier (1786-1858) und in St. Petersburg beim Freund Schukowskij in dessen Kunstsammlung zumindest mit Einzelwerken Friedrichs in Berührung, denn Schukowskij besaß immerhin mindestens acht Gemälde und 50 Zeichnungen von Friedrichs Hand ${ }^{23}$ Insofern kann man Asvarishchs Feststellung zustimmen: "Mountains [(Abb. 1)] and Sea Bay [(Abb. 2)] by August Hagen are curosities, of interest for their apparent likeness to the works of Friedrich, although no great effort is required to establish the fact that this likeness is purely superficial. There can be no question of any direct influence by Friedrich on this university teacher of drawing at Derpt (Tartu): he never met the German artist, but he did see his paintings in Derpt, in the home of a university professor, I. F. Moyer (1786-1858), and in Zhukovsky's possesion in St Petersburg". ${ }^{24}$ Doch scheint es m. E. nicht nur bei einer oberflächlichen Annäherung Hagens an Friedrichs Motivwelt, an dessen Lichtinszenierungen und Kompositionsmuster geblieben zu sein, die als Stimmungs- und Bedeutungsträger eine romantische Weltsicht vertreten. Vielmehr klingt in der einsamen Landschaft

21 Vgl. Gerd Heinz-Mohr, Lexikon der Symbole. Bilder und Zeichen der christlichen Kunst (München: Diederichs, 1978), 176-180.

22 Vgl. den Briefwechsel zwischen C. D. Friedrich und Schukowskij, u. a. den Erwerb von dessen Werken für den Petershofer Zarenhof betreffend, in Caspar David Friedrich. Die Briefe, hrsg. Hermann Zschoche (Hamburg: ConferencePoint Verlag, 2005), Briefe Nr. 110 (Februar 1828); Nr. 114 (9. Februar 1830), Nr. 131 (14. Oktober 1835), Nr. 133 (19. November 1835), Nr. 134 (12. Dezember 1835), Nr. 136 (16. August 1836) bzw. Boris I. Asvarishch, "Friedrichs russische Auftraggeber", Caspar David Friedrich. Gemälde und Zeichnungen aus der UdSSR, hrsg. Sabine Rewald (München, Paris, London: Verlag Schirmer/Mosel, 1991).

23 Vgl. Asvarishch, "Friedrichs russische Auftraggeber", 36.

24 Asvarishch, "Caspar David Friedrich in Russia", 72-73. 


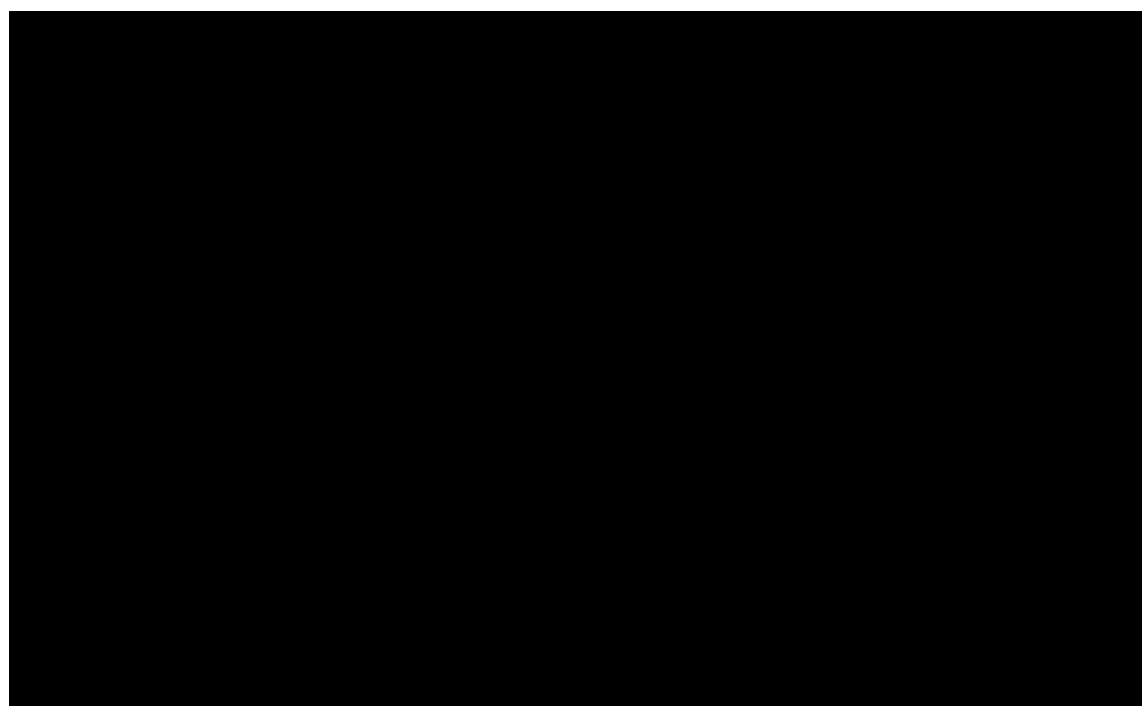

Abb. 6. August Matthias Hagen, Landschaft im Mondlicht, Ölgemälde, 1835. Ermitage.

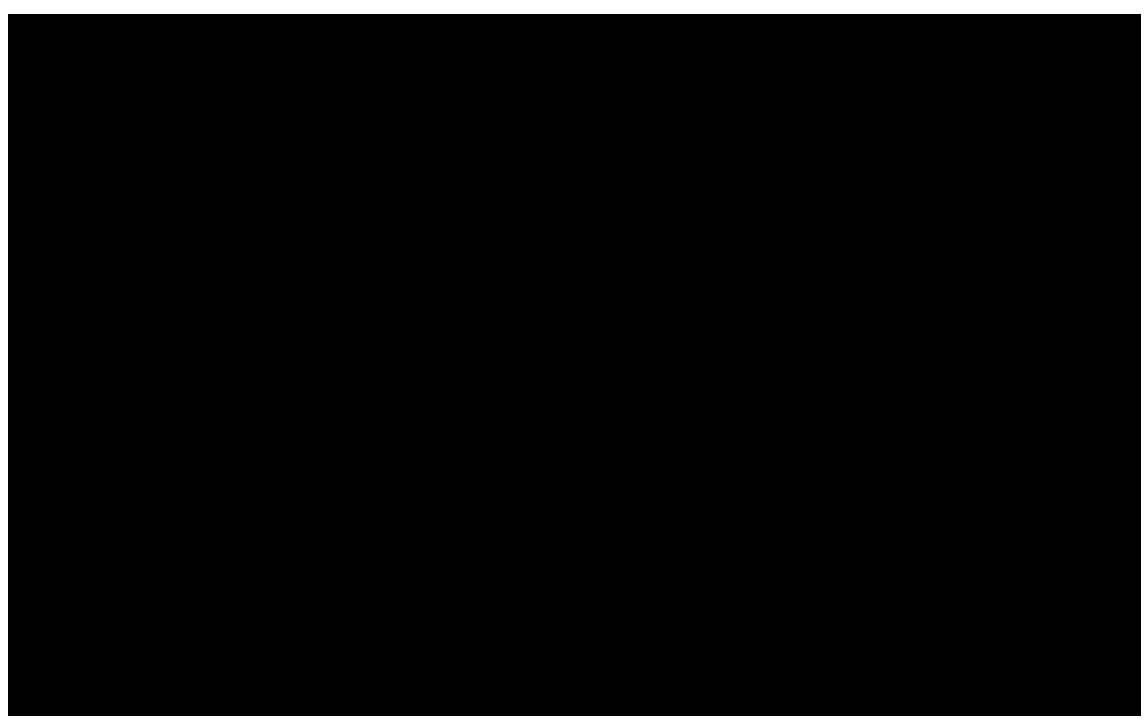

Abb. 7. August Matthias Hagen, Abend in einem Dorf, Sepia und Tusche, 1835. Estnisches Historisches Museum. 


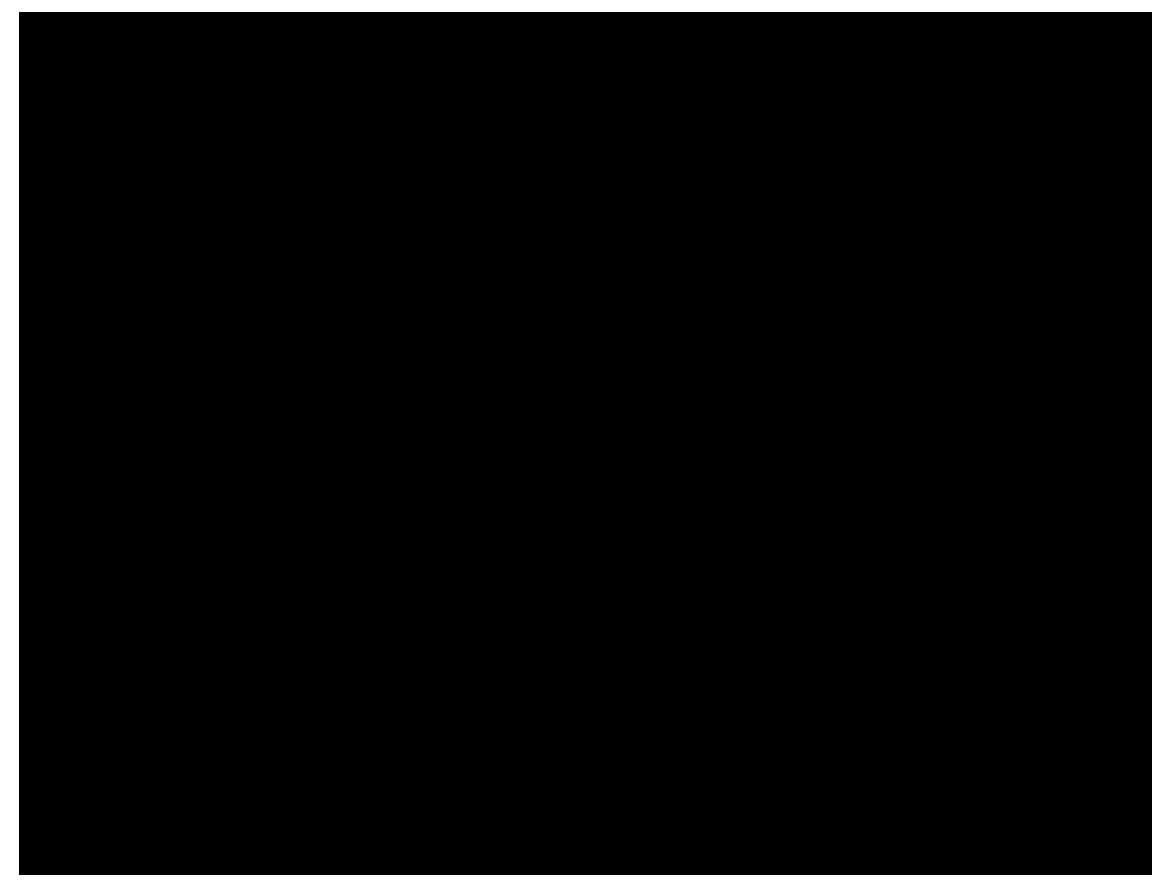

Abb. 8. August Matthias Hagen, Ansicht von Hogland, Ölgemälde, 1839. Estnisches Kunstmuseum.

im Mondschein (Abb. 6) und in dem stimmungsvollen Abend in einem Dorf (Abb. 7) mit untergehender Sonne ein mit Friedrich vergleichbares Weltgefühl an, das ebenfalls auf Transzendenz gerichtet ist und etwas von der Bedeutungslosigkeit und Armseligkeit des Individuums im Universum erahnen lässt, von dessen Tragik sich Schukowskijs Dorpater Kreis ${ }^{25}$ inspiriert sah. Doch war diese von Friedrich verfolgte romantische Position in den dreißiger Jahren des 19. Jahrhunderts bereits schon so stark im Abklingen begriffen, dass sie Hagen nur kurzzeitig beibehielt bzw. sich an ihr orientierte und stattdessen fortan wieder stärker

25 Neben August Matthias Hagen und dem Professor für Geschichte und Rektor der Universität Dopat, Johann Philipp Gustav (von) Ewers (1781-1830), gehörte zum Dorpater Freundeskreis Schukowskijs vor allem der Chirurg und spätere Rektor der Universität Dorpat, Johann Christian Moier (1786-1858) - ein Sammler von Werken Caspar David Friedrichs und ein exzellenter Musiker - dem Schukowskij einen besseren Zugang zur Musik und die Begegnung mit Werken Friedrichs noch vor seiner persönlichen Bekanntschaft in Dresden verdankte, wo er beglückend feststellte, dass er mit "ihm dieselben Auffassungen von dem Wesen und Ziele der Kunst, nämlich die Überzeugung, daß die Hauptsache in der Malerei die Treue zur "unsichtbaren Wahrheit" und die Darstellung der Seele in der Natur" teile. Kobilinski-Ellis, "Das goldene Zeitalter russischer Poesie", 174, siehe auch S. 134, 138-139, 141-142. Vgl. Aleksandra O. Smirnova-Rosset, Dnevnik. Wospominanija (Moskva: Nauka, 1989), 369. 
Abb. 9. August Matthias Hagen, Blick über die Insel Hogland im Finnischen Meerbusen, Ölgemälde, 1840. Privatbesitz.

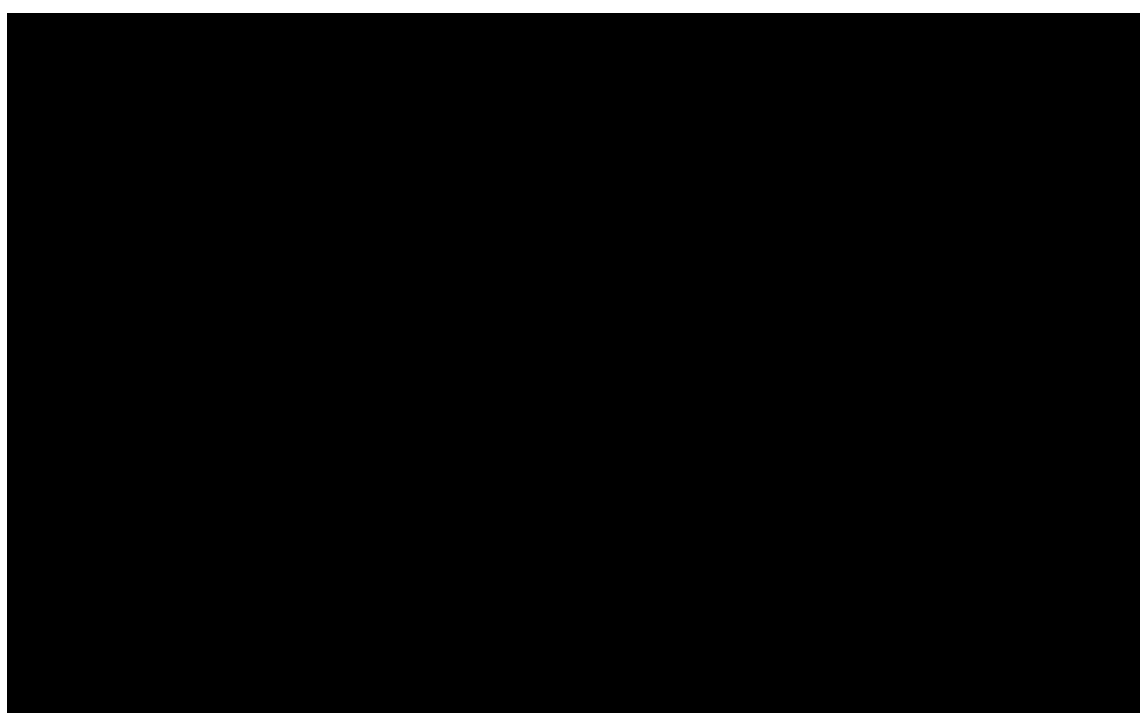

Abb. 10. August Matthias Hagen, Nebel im Hochgebirge, Ölgemälde, 1840. Privatbesitz. 
eine realistische Haltung bezog, wie sie in Dresden vor allem durch Friedrichs norwegischen Freund Johan Christian Clausen Dahl (17881857) favorisiert wurde.

\author{
VON CASPAR DAVID FRIEDRICHS \\ FRÜHROMANTISCHEN VISIONEN HIN ZU \\ JOHANN CHRISTIAN CLAUSEN DAHLS \\ "ROMANTISCHEM REALISMUS"
}

In der Tat zeigt sich in Hagens Schaffen auch eine große Affinität zu diesem Meister aus dem Friedrich-Kreis. Beispiele hierfür bieten Hagens Darstellungen Ansicht von Hochland/Suursaari (Abb. 8), Blick über die Insel Suursaari/Hogland im Finnischen Meerbusen ${ }^{26}$ (Abb. 9) oder Nebel im Hochgebirge (Abb. 10), die 1839 und 1840 entstanden sind. In ihnen spielt die einfühlsam beobachtete, schroffe, unwirtliche Landschaft Skandinaviens die dominierende Rolle, deren erhaben wirkende Einsamkeit und Kälte in ihrer Weite und Majestät eindrucksvoll geschildert wird, ohne dabei philosophisch-religiöse Anspielungen romantischer Transzendenz und Gottessehnsucht anklingen zu lassen; vielmehr kommt dabei eine stimmungsvolle, poetische Weltsicht zum Tragen, die jeweils die dargestellte Natur als Wunderwerk Gottes versteht, die sich dem Menschen durch Einfühlung auf großartige Weise offenbart. Eine klare, detailgetreue Gestaltungsweise, die die Wirklichkeit möglichst unverfälscht und dennoch mit den Reizen einer stimmungshaft-poetischen Sicht wiedergibt, dank der sich das Wesen des jeweiligen Landschaftscharakters im Atmosphärischen erschließt, ist die Absicht des romantischen Realismus ${ }^{27}$, zu dem der Norweger Dahl 1819 mit seinem Waldbach im Gebirge (Abb. 11) ${ }^{28}$ die Bahn in der deutschen Landschaftsmalerei brach und so auch den Weg bereitete, den Hagen dann seit den 1840er Jahren konsequent weiter verfolgte. Ludwig Richter (1803-1884) berichtet in seinen Lebenserinnerungen

26 Vgl. Jensen, "Einwirkungen Caspar David Friedrichs auf August Matthias Hagen. Die Insel Suursaari im Werk des baltischen Malers", 201, Abb. Kat. Nr. 51. Das 1840 datierte Werk wiederholte Hagen 1861 noch einmal mit geringfügigen Variationen. Es befindet sich heute im Estnischen Kunstmuseum in Tallinn, vgl. Vaga, Kunst Tartus XIX sajandil, Abb. 67.

27 Vgl. Hans Joachim Neidhardt, Die Malerei der Romantik in Dresden (Leipzig: Ebeling, 1976), $160-200$.

28 Vgl. Friedrich von Boetticher, Malerwerke des neunzehnten Jahrhunderts. Beitrag zur Kunstgeschichte von Friedrich von Boetticher, Erster Band (Leipzig: Schmidt \& Günther, 1948), 210, Nr. 2; Hans Ebert, Kriegsverluste der Dresdener Gemäldegalerie. Vernichtete und vermisste Werke (Dresden: Staatl. Kunstsammlungen, 1963), 88, Nr. 2206 (seit dem Zweiten Weltkrieg vermisst). 
von der spektakulären Wirkung, die seinerzeit Dahls Aufnahmebild für die Dresdner Kunstakademie auf der Ausstellung von 1819 auslöste: “Denn es war jetzt ein junger Norweger nach Dresden gekommen, welcher unter den Studierenden große Sensation erregte. Es war Christian Dahl. Eine große norwegische Gebirgslandschaft von ihm auf der Kunstausstellung machte das ungeheuerste Aufsehen, und schwerlich kann man sich jetzt eine Vorstellung machen, welche Wirkung ein Werk von solcher schlagender

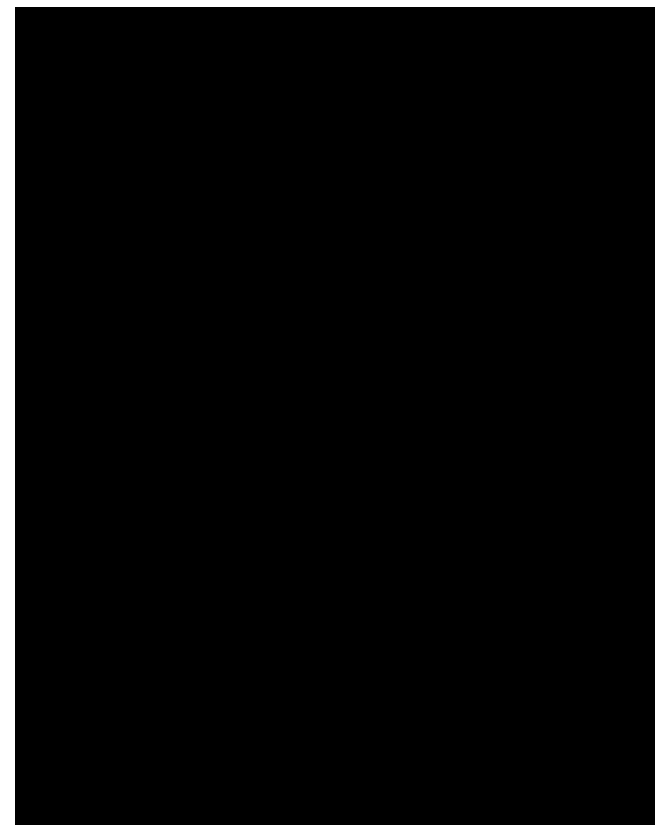

Abb. 11. Johan Christian Clausen Dahl, Waldbach im Gebirge, Ölgemälde, 1819. Staatliche Kunstsammlungen Dresden (Kriegsverlust). Naturwahrheit unter dem

Troß der übrigen schattenhaften, leblosen, maniervollen Gemälde hervorbrachte. Nur Dahls Freund Friedrich machte davon eine Ausnahme mit seinen ganz originellen, poetisch gedachten und tief melancholischen Landschaftsbildern. Die älteren Professoren lächelten freilich über diese Ketzereien oder Narrheiten; von den jüngeren wurden sie bewundert und nach Kräften nachgeahmt. Der Frühlingsodem einer neuen Zeit fing an seine Wirkung zu äußern, das alte Zopftum war im Absterben, belächelte aber in olympischer Sicherheit den tollen Rausch der jungen Sprößlinge". ${ }^{29}$ Die Kenntnis von Dahls Schaffen wird gewiss ebenfalls über Schukowskij zu Hagen gelangt sein, zumal seine "Gegenposition zu Friedrichs Landschaftsauffassung im Grunde nichts der Romantik Fremdes [bedeutete]" ${ }^{\prime 30}$, vielmehr nur die Kehrseite ein und derselben Medaille bildete, so dass Hagen diese Spur des romantischen Realismus in seinem späteren Schaffen nahezu bruchlos weiterverfolgen konnte,

29 Ludwig Richter, Lebenserinnerungen eines deutschen Malers nebst Tagebuchaufzeichnungen und Briefen, hrsg. Erich Marz (Leipzig: Dieterich'sche Verlagsbuchhandlung, 1950), 65.

30 Neidhardt, Die Malerei der Romantik in Dresden, 161. 


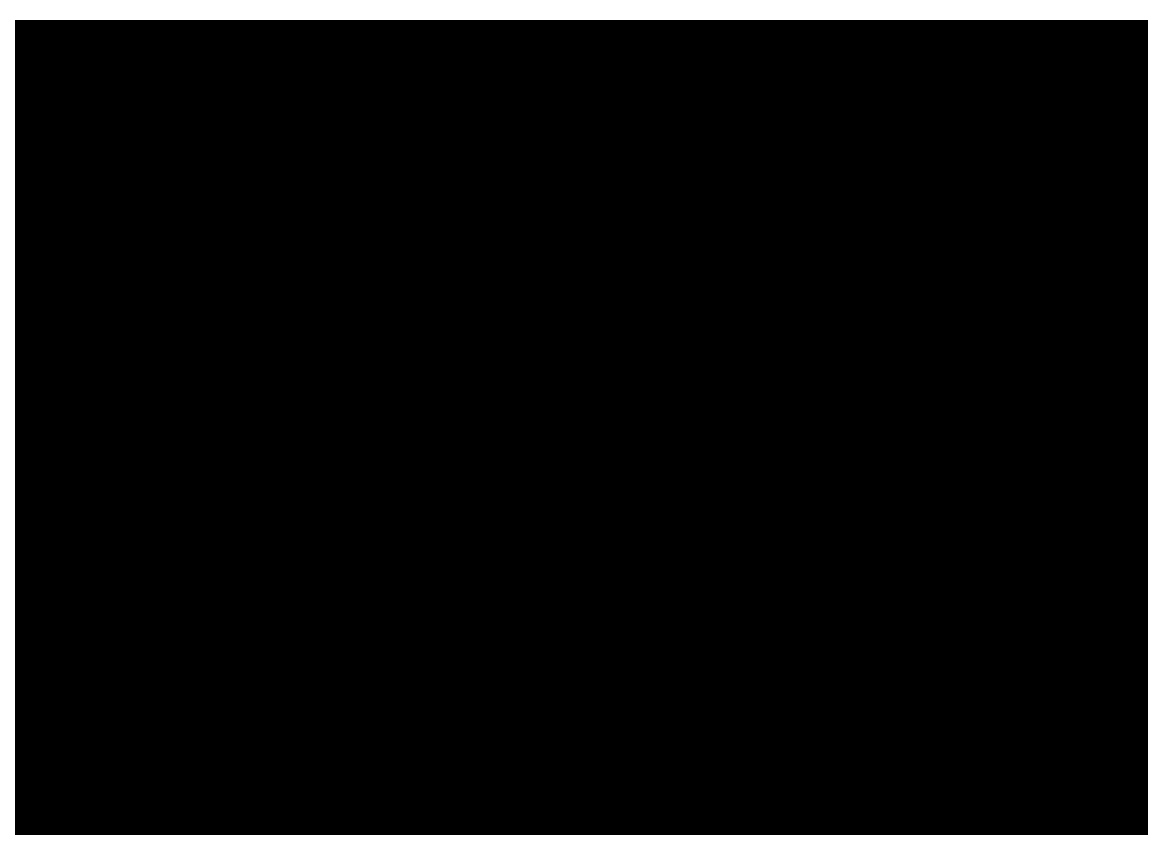

Abb. 12. August Matthias Hagen, Villa Massimo, Rom, Bleistift und Sepia, 1852. Privatbesitz.

wie es sich u. a. in seinen Sepiazeichnungen aus Rom von 1852 zeigt, die mit der Villa Massimo (Abb. 12) und der Villa Malta (Abb. 13) - letztere sogar gleich im Motiv - ein hohes Maß an Übereinstimmung zu Dahls Auffassung aufweisen ${ }^{31}$.

\section{RÜCKBLICK - DIE ANFÄNGE VON A. M. HAGENS KUNSTSCHAFFEN VOR DER SPIRITUELLEN BEGEGNUNG MIT DER KUNST DER DRESDNER ROMANTIK}

Doch ehe wir weiter die künstlerische Entwicklung in Hagens Kunstschaffen nach dessen Berufung am 10.05.1838 zum Zeichenlehrer an der Universität Dorpat in der Nachfolge von Carl August Senff (17701838) verfolgen, wollen wir zunächst einen Blick auf die Anfänge des Künstlers lenken. Auskunft darüber erhalten wir teilweise aus einer un-

31 Vgl. Johan Christian Clausen Dahl, Villa Malta. Garten bei einer römischen Villa. 1821. 34,5x38,5 cm, Nasjonalgalleriet Oslo, Inv.-Nr. 2270 (Bang 329). Vgl. Johan Christian Dahl 1788-1857. Ein Malerfreund Caspar David Friedrichs, hrsg. Christoph Heilmann u. a. (München: Edition LippVerlag, 1988), 124-125. 


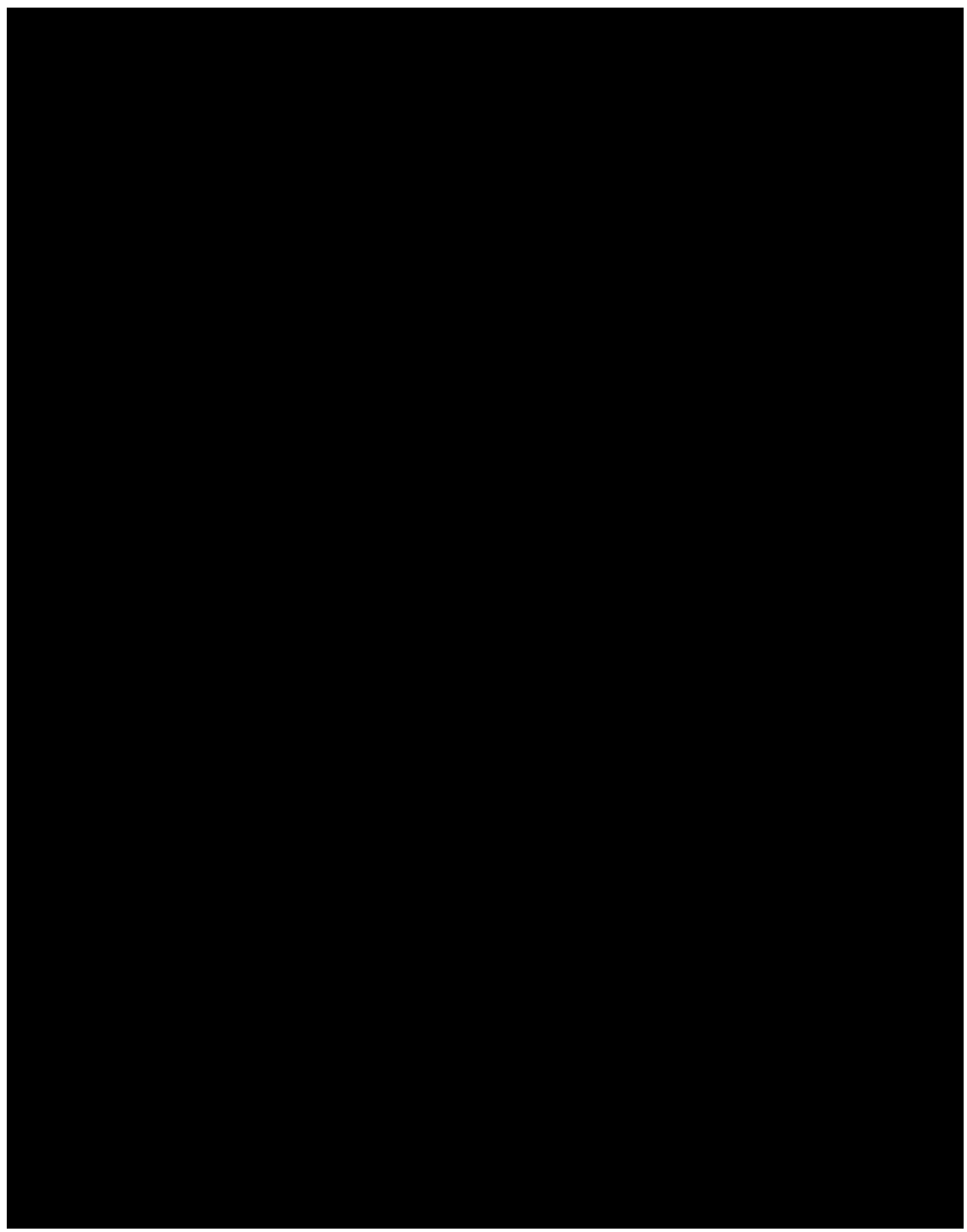

Abb. 13. August Matthias Hagen, Villa Malta, Rom, Sepia, 1852. Estnisches Kunstmuseum.

vollendet gebliebenen Autobiographie, die mit der Datierung vom 22. Januar 1857 in Hagens Nachlass erhalten ist. ${ }^{32}$ Daraus geht hervor, dass er am 12. Februar 1794 in Wiezemhof (Vijciems) in Livland, im Kirchspiel

32 Eine Kopie davon befindet sich im Besitz des Autors. 


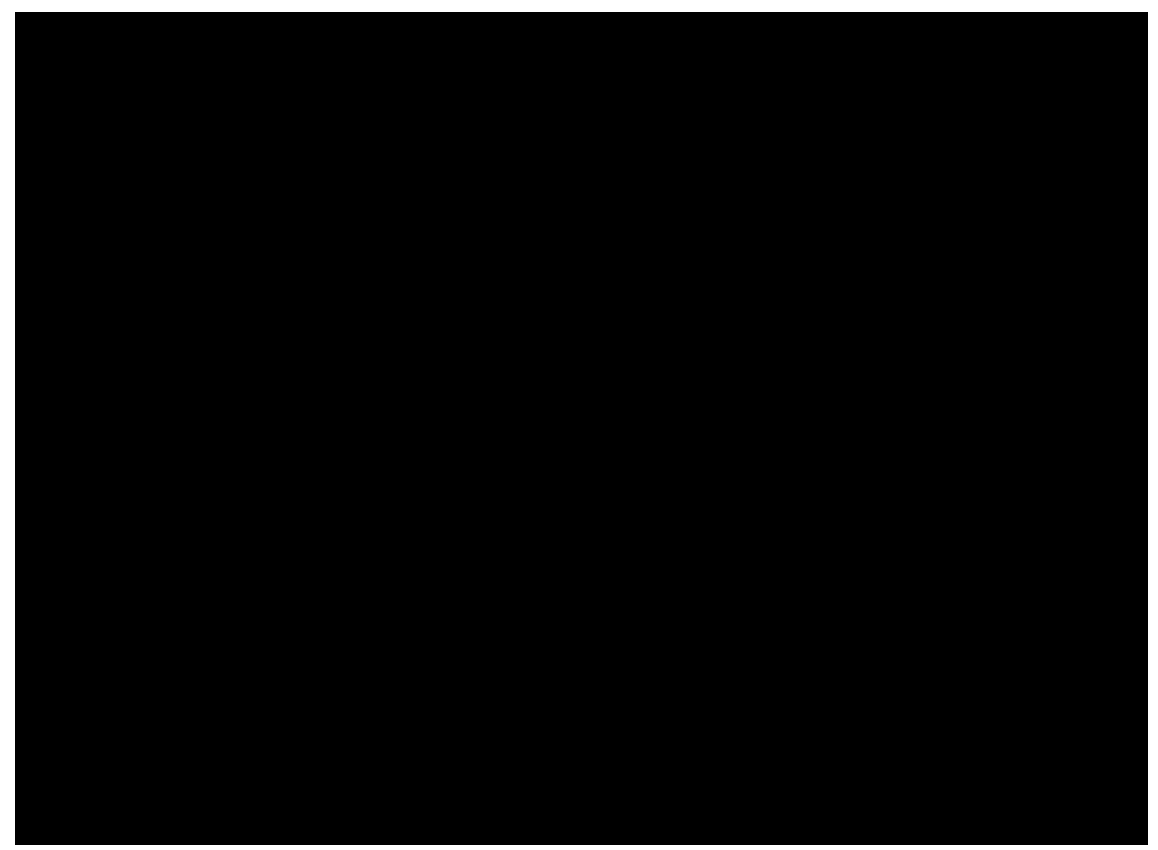

Abb. 14. August Matthias Hagen, Südliche Ansicht der Stadt Wenden, Kolorierte Radierung, ca 1832-1833. Tartuer Kunstmuseum.

Trikaten (Trikata kihelkond), etwa $20 \mathrm{~km}$ südlich von Walk (Valga) gelegen, als Sohn des Mühlenpächters Ernst Andreas Hagen und dessen Ehefrau Christine Dorothea Busch geboren wurde. ${ }^{33}$ Nach seinem 1809 erfolgten Schulabschluss in Wenden (Cēsis) begann er 1810 eine Lehre beim Stubenmaler Oberg in Dorpat und wurde dort schon 1811, also im Alter von 17 Jahren, Schüler und Assistent von Carl August Senff (1770-1838). Diese Ausbildung dauerte nur kurz und blieb für den jungen Eleven der Kunst ziemlich unbefriedigend, weil er neben dem Studium der Blumen- und Landschaftsmalerei hauptsächlich mit dem Drucken von Vorlagenblättern für den Kunstunterricht beschäftigt wurde, sodass nur wenig Zeit für die eigentliche künstlerische Ausbildung übrig blieb. Deshalb meldete er sich schon im Sommer 1813 als Freiwilliger bei der russischen Armee, um in den Vaterländischen Krieg gegen Napoleon zu ziehen. Aus der Zeit nach der Rückkehr aus dem Kriege sind die frühesten Arbeiten Hagens erhalten. Es handelt sich dabei um einige Skizzen

Nach altem julianischen Kalender war dies der 23. Februar 1794. 
und Veduten aus der livländischen Heimat, die in ihrer klassizistischen Exaktheit noch die Auffassung seines Lehrers Senff verraten. Das betrifft in erster Linie die kolorierten und unkolorierten Radierungen mit der Südlichen Ansicht der Stadt Wenden (Abb. 14) und mit der Südwestlichen Ansicht der Ruine von Schloss Wenden ${ }^{34}$, sowie der Xylographie mit der topographisch exakten Darstellung der Ruine der Domkirche Dorpat ${ }^{35}$, deren Chor von 1804 bis 1807 durch Johann Wilhelm Krause (1757-1828) zur Universitätsbibliothek umgebaut worden war. Als skizzenhaft flüssig gemaltes Aquarell, das ganz im Sinne des aufkommenden malerischen Realismus der frühen Freilichtmalerei gefertigt wurde, erweist sich die Ansicht der Ruine der Burg Neuhausen im Kreis Werro (Võru/Livland) ${ }^{36}$, die der Künstler signierte, mit "Aprill 1820" datierte und mit der Inschrift "Ruine bei Neuhausen an der russischen Grenze" versah; ein kleines Werk, das durch seine Unmittelbarkeit und spontane Frische erfreut.

\section{HAGENS STUDIENREISE NACH DEUTSCHLAND, BÖHMEN, ÖSTERREICH UND DIE SCHWEIZ \\ UND DIE BEGEGNUNG MIT DER DEUTSCHEN KUNST ALS VORAUSSETZUNG SEINER SENSIBILISIERUNG FÜR DIE IDEALE DER DEUTSCHEN ROMANTIK}

So künstlerisch vor allem im Landschaftsfach präpariert, begab sich Hagen am 30. Juni 1820 auf Wanderschaft und machte sich auf zu einer langjährigen Studienreise, die ihn nach Deutschland, Österreich und in die Schweiz führte. In Boltera bei Riga bestieg er einen Segler, um nach Lübeck zu reisen. In drei Tagebüchern berichtet er ausführlich über den Verlauf der Reise und über die dabei gemachten Erfahrungen und Erlebnisse. ${ }^{37}$ Zugleich belegen zahlreiche Zeichnungen und Skizzen vi-

34 August Matthias Hagen, Südwestliche Ansicht der Ruine von Schloss Wenden, Radierung, 297x397 mm, KM Tartu 221 D; August Matthias Hagen, Südwestliche Ansicht der Ruine von Schloss Wenden, Kolorierte Radierung, $301 \times 406$ mm, KM Tartu 1256 G, vgl. Krüger, Die Zeichenschule der Universität Dorpat 1803-1891, 14.

35 August Matthias Hagen, Ruine des Doms St. Peter und Paul zu Dorpat, Xylographie 214x288 mm, KM Tartu 1234 G, vgl. Krüger, Die Zeichenschule der Universität Dorpat 1803-1891, 14, Abb. S. 16.

36 August Matthias Hagen, Ruine der Burg Neuhausen im Kreis Werro (Livland), 1820, Aquarell, 240x340 mm, UB Tartu 3667, vgl. Krüger, Die Zeichenschule der Universität Dorpat 1803-1891, Abb. S. 15.

37 Vgl. August Matthias Hagen, Tagebuch einer Reise nach Deutschland, Band I, Juli bis Oktober 1820, hrsg. Peter Schwarz (Dresden, 2007); August Matthias Hagen, Alpenreise. Tagebücher, Bände II, III, Oktober 1820 bis Oktober 1821, hrsg. Peter Schwarz (Dresden, 2009). 
Abb. 15. August Matthias Hagen, Grabstätte Theodor Körners in Wöbbelin, Tusche, 1820. Privatbesitz.

suell die interessantesten Eindrücke, die er auf dieser Reise gemacht hat, die ihn zunächst von Lübeck über Schönberg, Hamburg, Bergedorf und Büchen zu Körners Grab im Dorfe Wöbbelin bei Ludwigslust geführt hat, wo er am 8. August 1820 des tapferen Kämpfers für Deutschlands Freiheit gedachte: “Morgens um 8, nachdem ich mir meinen Paß gelöst hatte, setzte ich meine Wallfahrt nach des Geliebten Grabe fort und bereue es nicht, dagewesen zu sein. Der Schulze wird von dem Herzog dafür besoldet, jedem Reisenden dieses Grab zu zeigen. Freundlich schloß 
er es auch mir auf und ein heiliger Schauer umwehte mich. Ich bat um die Erlaubnis, es zeichnen zu dürfen, und er bewilligte es gerne [(Abb. 15)]. An dem Baume fand ich das Schwert eines seiner Waffenbrüder, der fürs Vaterland gefallen war und vor seinem Tode gewünscht hatte, hier, wenn nicht gleich seinen Leichnam, doch sein Schwert aufbewahrt zu sehen, seine Schwester ruht neben ihm". ${ }^{38}$ Mit seiner Zeichnung zollte Hagen dem im Kampf gegen Napoleon gefallenen Waffenbruder die letzte Ehre. Er ließ sich vom Geist der nationalen Selbstbesinnung der deutschen Romantiker inspirieren, die damals unter den Bedingungen der Metternich'schen Restriktionspolitik in der intellektuellen Jugend zu einem neuen Höhepunkt gefunden hatte.

Danach ging die Wanderung weiter über Ludwigslust, Perleberg, Berlin, Potsdam, Treuenbrietzen, Herzberg und Mühlberg nach Dresden, wo er einige Tage blieb, um sich mit dem gesellschaftlichen und künstlerischen Leben sowie mit der landschaftlich reizvollen Umgebung vertraut zu machen. Neben Tharandt, Pillnitz, der Sächsischen Schweiz und dem Königstein bildeten die Besichtigung von Moreaus Monument auf der Räcknitzhöhe ${ }^{39}$ und der Besuch der Dresdner Gemäldegalerie die Höhepunkte seines Dresden-Aufenthalts. Anschließend begab er sich nach Pirna, wo er am 10. September in seinem Tagebuch vermerkte: "Pirna gab mir reichlichen Stoff für das Studium des unbestimmten in einer Landschaft, und ich ergötzte mich mehr als eine Stunde an dies herrliche Schauspiel, der Sonnenschein, die Kirchtürme, das Gebüsch und die Bäume vor der Stadt gaben so viele mannigfaltige Gründe, daß ich durch diesen Anblick Clereau de Lorenz [gemeint ist Claude Lorrain - Anm. GHV] erst verstehen lernte ${ }^{\prime \prime 40}$, d. h., Hagen begann nun ein künstlerisches Gefühl für das Licht und seine stimmungshafte Wirkung zu entwickeln, die er dann in den dreißiger Jahren in sei-

38 Hagen, Tagebuch einer Reise nach Deutschland, 34.

39 Vom 25. bis 27.08.1813 tobte auf der Räcknitzhöhe südlich von Dresden die letzte große Schlacht im Kampf gegen Napoleon vor der Leipziger Völkerschlacht. Hier zog sich am 27. August 1813 der auf russischer Seite kämpfende General Jean Victor Moreau (1761-1813) seine tödliche Verwundung zu. Der Architekt Gottlob Friedrich Thormeyer, der neben Christian Leberecht Vogel in Dresden zu Carl August Senffs Freundeskreis gehörte, entwarf auf Initiative des russischen Generalgouverneurs in Dresden, Fürst Repnin-Wolkonski, den Entwurf des Monuments, das 1814 zur Erinnerung an den in russischen Diensten kämpfenden französischen General, der hier durch eine Kanonenkugel beide Beine verlor und wenige Tage später an den Folgen dieser Verwundung im böhmischen Laun (Louny) verstarb. Die bildhauerische Ausführung des Denkmals übernahm Christian Gottlieb Kühn, ein Freund Caspar David Friedrichs. Hagens Besuch der Gedenkstätte erklärt sich aus seiner antinapoleonischen Haltung, die er während des Vaterländischen Krieges auf russischer Seite vertrat.

40 Hagen, Tagebuch einer Reise nach Deutschland, 62. 


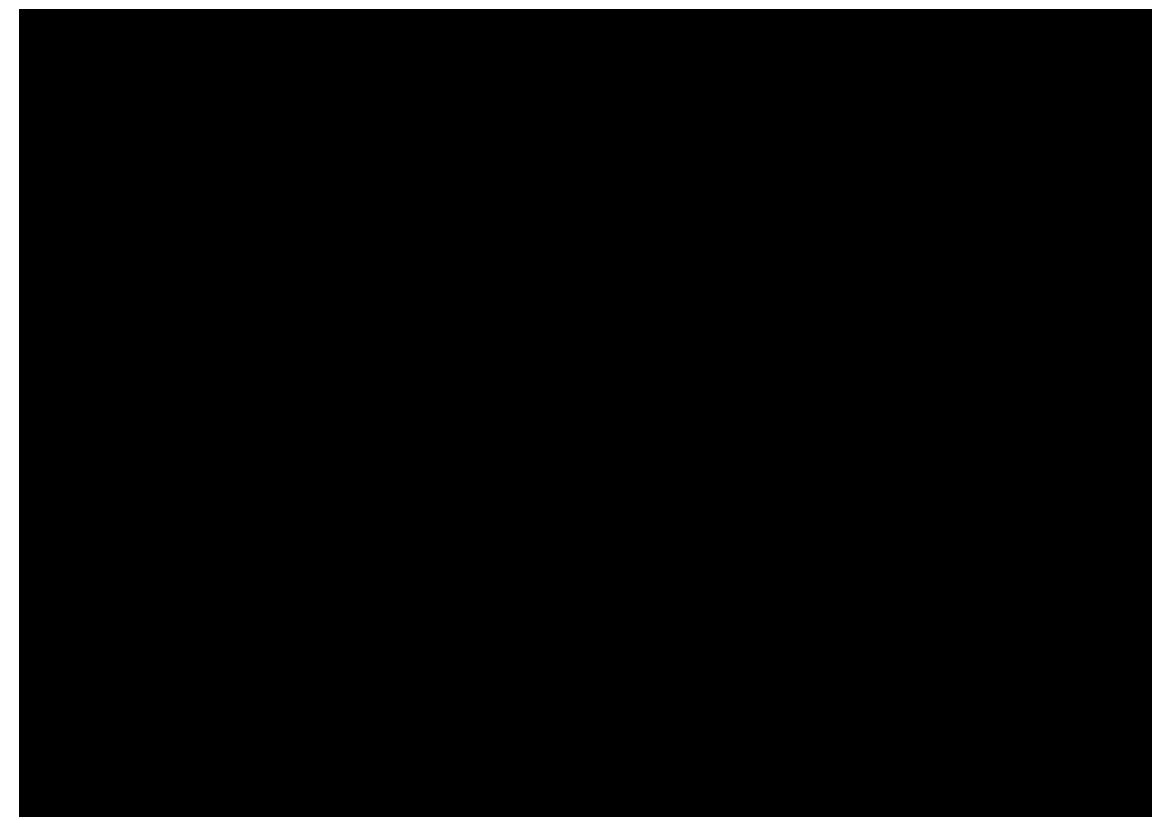

Abb. 16. August Matthias Hagen, Spaziergang in Passau, Ölgemälde, 1820. Standort unbekannt.

nem Schaffen zu ihrem romantischen Höhepunkt deutschbaltischer Landschaftsmalerei führte. Das Erleben der Sächsischen Schweiz und Nordböhmens in den darauffolgenden Tagen bereitete ihm zweifellos Erlebnisse, die jenen ähnlich waren, wie sie dort schon Caspar David Friedrich bei seinen Wanderungen erfahren hatte. Über Prag, Iglau und Kuttenberg führte der Weg weiter nach Wien. Dort verbrachte er kaum eine Woche, um schließlich vor Einbruch des Winters über St. Pölten, Melk, Ens und Linz noch bis Passau vorzustoßen, wo er am 11. Oktober eintraf, um hier bis zum kommenden Frühjahr zu überwintern. Wichtig wurden ihm in dieser Zeit die Begegnung mit dem Passauer Maler Anton Berger (1775-?), bei dem er wohnte, und der Besuch der dortigen Kunstschule, die unter der Leitung eines Prof. Eichler stand. Mehrere Studien von der Stadt und ihrer Umgebung sind seinerzeit entstanden, darunter das Ölgemälde Spaziergang in Passau von 1820 (Abb. 16) ${ }^{41}$ oder 1822 eine Ansicht Passaus aus der Ferne (Abb. 17). In Passau lernte er auch Johanna von Paumgarten (15.02.1802-20.01.1885), seine spätere Ehefrau

41 Vgl. “August Mattias Hagen”, Парашутові (02.10.2013), http://www.liveinternet.ru/users/2010239/ post293779207/ (zuletzt aufgerufen 12.11.2015). 


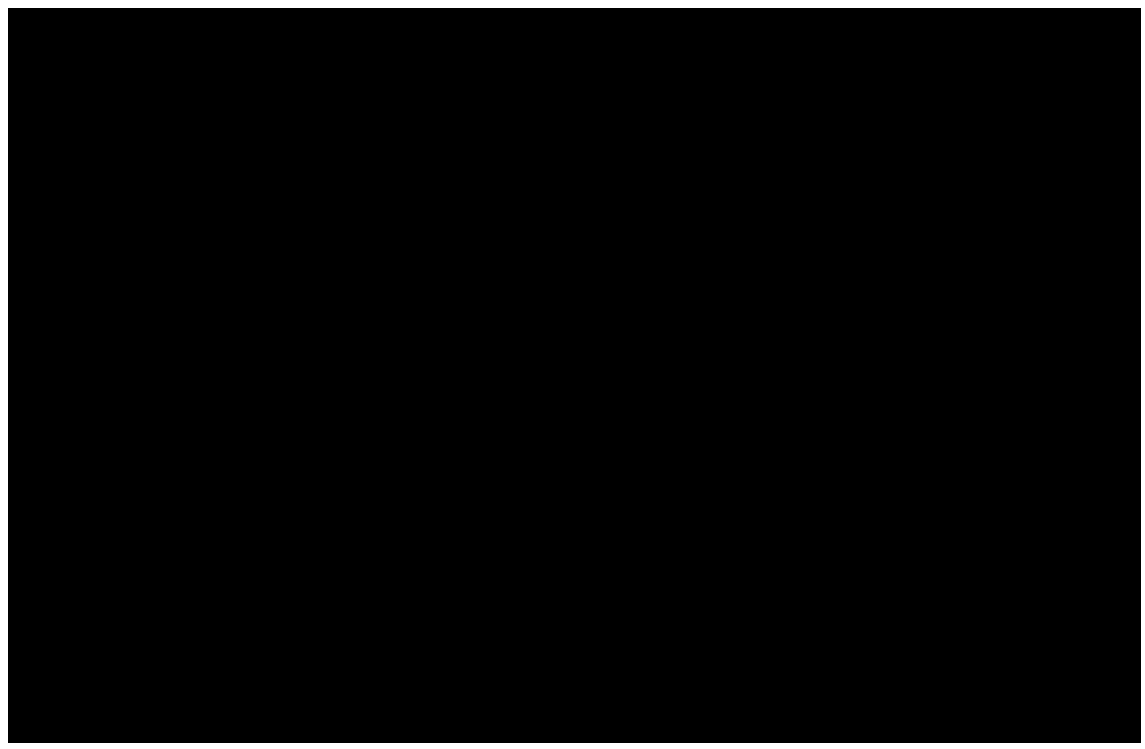

Abb. 17. August Matthias Hagen, Ansicht von Passau aus der Ferne, Federzeichnung, 1822. Estnisches Kunstmuseum.

und Mutter seiner zehn Kinder, kennen. Im Frühjahr 1821 verließ er sie für vier Monate, um seine Studienreise durch die Alpen, während der er fleißig skizzierte, fortzusetzen. Am 10. Mai brach er in Passau auf. Über die Welser Heide, weiter nach Kremsmünster gelangte er ins Salzkammergut, ins Dachsteingebirge und in den Tennengau. Schließlich führte ihn im Juni der Weg über Salzburg nach Tirol und Voralberg, wo er bei Feldkirch die Grenze nach Graubünden überquerte. Chur, die Via Mala bei Thusis, der Vierwaldstätter See, das Berner Oberland, Fribourg und Lausanne gehörten in der Schweiz für ihn zu den beeindruckendsten Stätten, die er besuchte, bevor er Anfang September über Luzern, Zürich, Winterthur, St. Gallen, den Bodensee, das Allgäu, München und Landshut zu seiner Geliebten nach Passau zurück eilte, wo er am 15. September 1821 wieder eintraf. Ein Teil der großen Ausbeute seiner damals gefertigten Skizzen ist sowohl im Nachlass des Künstlers ${ }^{42}$ als auch in einigen musealen Sammlungen Estlands erhalten, darunter das Aquarell einer großartigen Alpenlandschaft (Abb. 18) oder die Sepia eines

42 Vgl. die zahlreichen Illustrationen, die seine Reisetagebücher ergänzen, in: Hagen, Tagebuch einer Reise nach Deutschland; Hagen, Alpenreise. Tagebücher. 


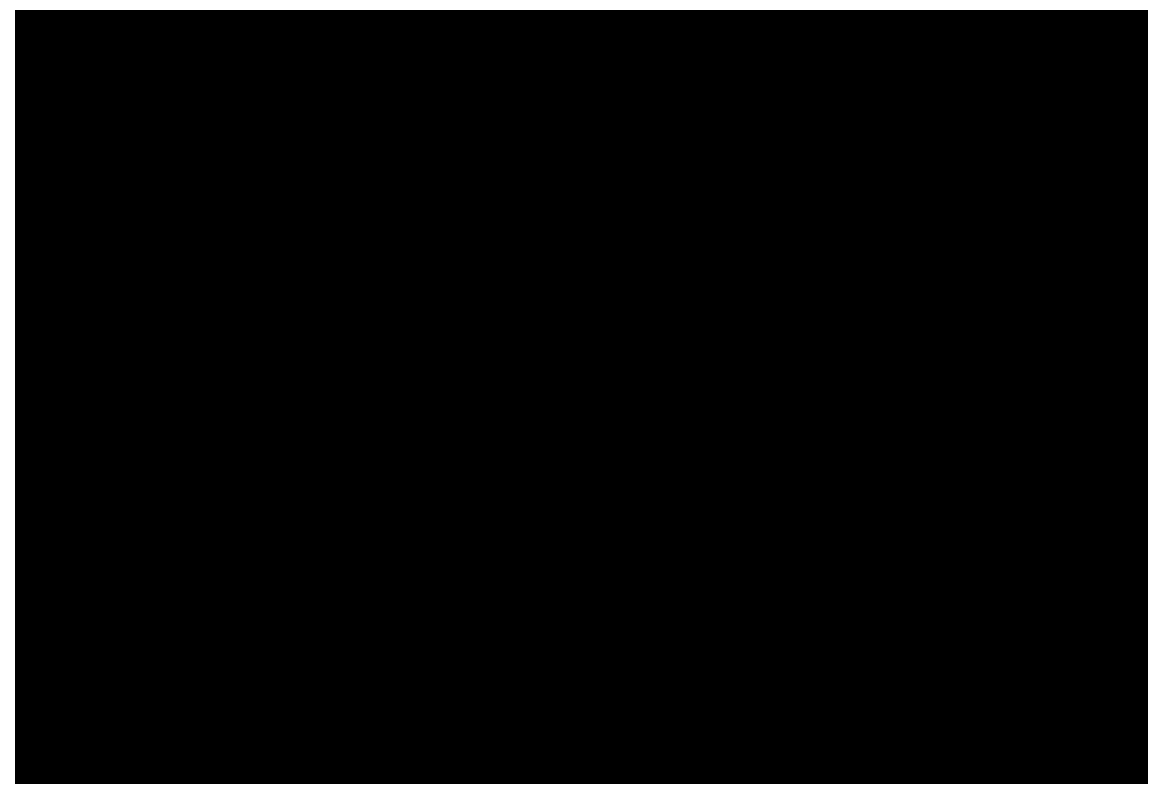

Abb. 18. August Matthias Hagen, Alpenlandschaft, Aquarell, Gouache und Tusche, ca 18211822. Universitätsbibliothek Tartu.

Abb. 19. August Matthias Hagen, Schweizer Bergtaldorf, Sepia, 1821. Estnisches Kunstmuseum. 


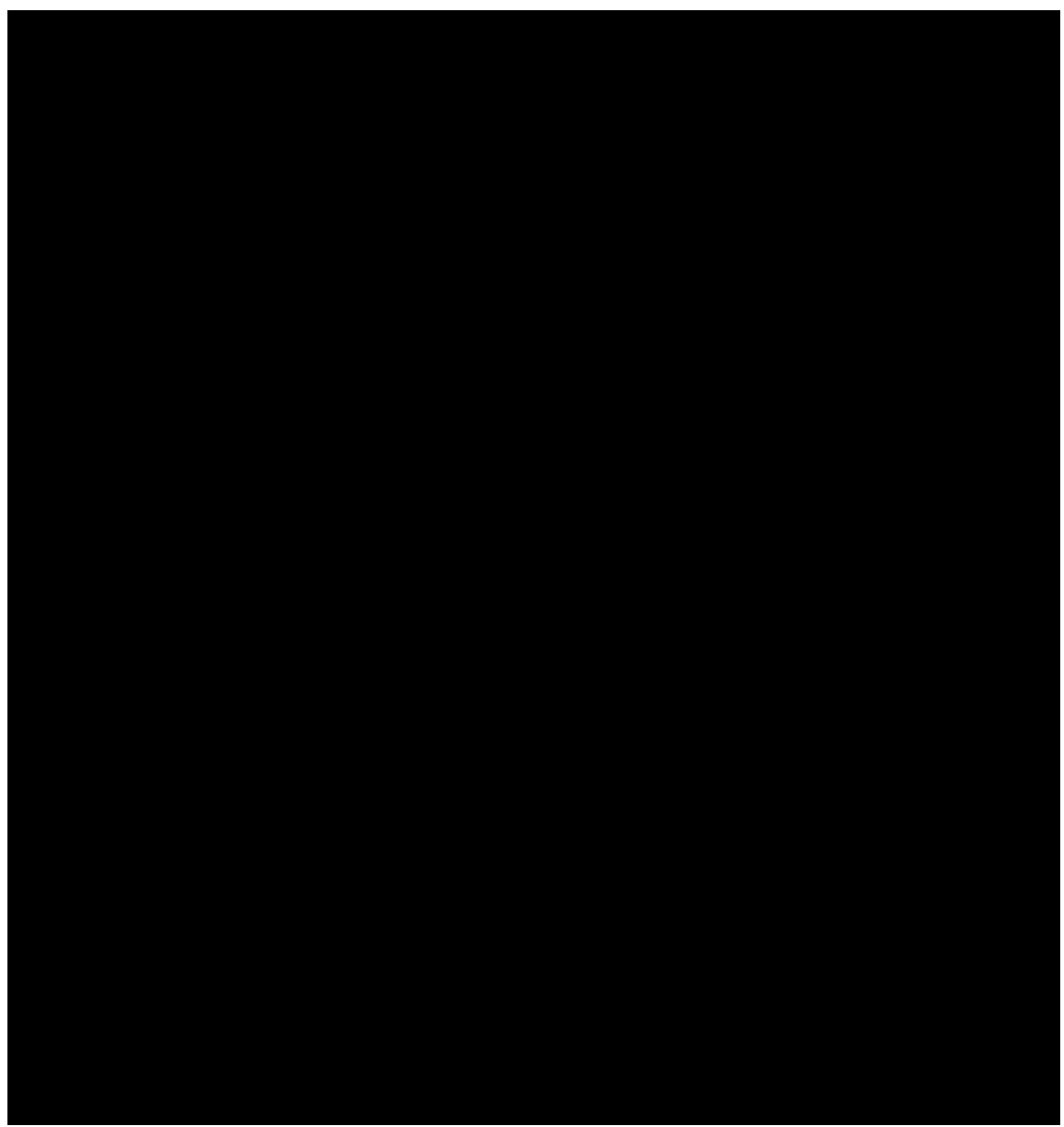

Abb. 20. August Matthias Hagen, Felsschlucht mit Wasserfall, Sepia und Gouache. Tartuer Kunstmuseum.

Schweizer Bergtaldorfs (Abb. 19) bei denen er die Konventionen der klassizistischen Landschaftsauffassung hin zum Romantisch-Stimmungsvollen durchbricht. Vor allem mit der Tuschzeichnung der Felsschlucht vom Mai 1822 (Abb. 20) hatte sich mit seiner detailgetreuen Beobachtung der Gesteinsformationen im Gebirge bereits jenes sensible Gespür für das "innere Naturleben" herauszuformen begonnen, das Carus später die "Erdlebenkunst" nannte, die in den Werken des kaiserlichen Auftrags zu den finnischen Landschaften ihren Höhepunkt in Hagens Schaffen erreichen sollte. Auf alle Fälle löste die Begegnung mit den Landschaften, wie 
sie wenige Jahre zuvor bereits die Generation der deutschen Romantiker studiert hatten, in Hagens Bewusstsein eine künstlerische Affinität in der ehrfurchtsvollen Betrachtung dieser Welt als Schöpfung Gottes aus, so dass er seit etwa der Mitte der 1830er Jahre - wohl unter dem Einfluss Schukowskijs - deren kunsttheoretischen und -praktischen Richtlinien mühelos in sein eigenes Schaffen zu adaptieren vermochte.

\section{RÜCKKEHR NACH LIVLAND UND ERSTE ILLUSTRATIONSARBEITEN FÜR DIE UNIVERSITÄT DORPAT}

Nachdem sich Hagen am 9. Februar 1823 mit seiner Jeanette vermählt hatte und im November desselben Jahres Karl, der erste Sohn, das Licht der Welt erblickte, trat die junge Familie die Rückreise nach Livland an, wo sie sich zunächst auf dem elterlichen Gut Klein Wrangelshof niederließ ${ }^{43}$ Hier wurden am 15.10.1824 die Tochter Julie Wilhelmine und am 17.02.1827 der Sohn Alexander geboren, die beiden Kinder, die beruflich in die Fußstapfen ihres Vaters traten und ebenfalls Maler wurden. Doch erst 1825 fand August Matthias Hagen als Zeichenlehrer am Gouvernements-Gymnasium in Dorpat eine feste Anstellung, die bald auf die dortige Töchterschule erweitert wurde, so dass er seine stetig wachsende Familie besser ernähren konnte. "Die definitive Anstellung erfolgte für beide Schulen am 29. September 1826 - Ungefähr 1827 u. 28 zeichnet er 6 große Ansichten der Universitäts-Gebäude in Dorpat, die er auch in Kupfer sticht". ${ }^{44}$ Anlass für diese Bildserie war der 25. Jahrestag der Wiedereröffnung der Universität Dorpat, ein Anlass, von dem sich der Künstler eine Beförderung des Verkaufs seiner Aquatinten an ein größeres Publikum versprach. Neben dem Universitätshauptgebäude, dem Anatomicum und der Bibliothek im Chor der Domkirche gehörte die Ansicht der Sternwarte mit dem seinerzeit größten Fernrohr in Europa zu den sehenswerten Universitätsbauten, die Hagen als akkurate Veduten für die Freunde der Dorpater Universität verewigte.

In Dorpat war damals zunächst die Kenntnis romantischer Bildfindungen im Stile der Dresdner Romantik nicht gefragt. Hier setzte man statt dessen auf bewährte Sehgewohnheiten, die bislang mit dem

43 Vgl. Handschriftlicher Auszug aus Julius Döring, Ostbaltisches Künstler-Lexikon, Bd. II (Mitau: Kurl. Prov. Museum), Eintrag 390 (Hagen, August Matthias).

44 Ibidem. 
Wirken von Carl August Senff vor allem die ästhetischen Ideale des akademischen Klassizismus verfolgten und die im Landschaftsfach entweder zur lieblichen Idylle oder zur realistischen, nüchternen Vedute tendierten. Bis zu den von Deutschland weit entfernten russischen Provinzen Est- und Livlands waren die avantgardistischen Ideale der sächsischen Frühromantik noch kaum vorgedrungen, geschweige, dass sie hier hätten fest Fuß fassen können.

Mit der Bildserie der Universitätsgebäude bahnte sich Hagen zugleich den Weg zu den Professoren der jungen Alma mater, die nun auf dessen künstlerische Tätigkeit aufmerksam wurden. Bedarf an wissenschaftlichen Illustrationen bestand vor allem im Bereich der Botanik, einem Fach, auf das Hagen durch die Ausbildung in der Blumenmalerei bei Senff bestens vorbereitet war. So lieferte er botanische Illustrationen, die zur Ausstattung der Icones plantarum novarum vel imperfecte cognitarum floram Rossicam, imprimis Altaicam, illustrantes ${ }^{45}$, der mit 500 Lithographien ausgestatteten Nachfolgepublikation von Carl Friedrich von Ledebours (1786-1851) vierbändiger Flora altaica ${ }^{46}$ vorgesehen war. Es handelt sich um "eine /---/ unter mehreren Künstlern aufgeteilte Bestellung /---/ für ein botanisches Prachtwerk, das auf Grund der Altai-Expedition von Prof. K. Fr. v. Ledebour zusammengestellt wurde. Die Zeichnungen wurden mit Tusche zum Teil nach Herbarien, zum Teil nach lebenden Pflanzen gemacht und mit Aquarellfarben koloriert. Die Illustrationen wurden auf Tafeln in großem Format gedruckt. /---/ Hagen zeichnete nach eigenen Angaben 30 unsignierte Pflanzendarstellungen für die "Flora Altaica".

45 Carl Friedrich von Ledebour, ICONES PLANTARUM NOVARUM VEL IMPERFECTE COGNITARUM FLORAM ROSSICAM; IMPRIMIS ALTAICAMILLUSTRANTES, Tom I-V, Riga, London, Paris 1829-1834, vgl. Claus Nissen, Die botanische Buchillustration. Ihre Geschichte und Bibliographie, Band II (Stuttgart: Hiersemann Verlags-Gesellschaft, 1951), 106, Nr. 1155. Hagen ist dort nicht mit unter den Künstlern aufgeführt, weil er seine Arbeiten nicht signiert hatte.

46 Carl Friedrich von Ledebour, FLORA ALTAICA, Vol. 1-4, Berlin 1829-1833. Das Werk ist ohne Illustrationen. Nach Tartu Riikliku Kunstimuuseumi almanahh 2 (1967), 70-80, Anm. 10, soll es eine im gleichen Zeitraum in Riga erschienene Ausgabe geben. Ob diese illustriert war, ließ sich nicht überprüfen. Bei Nissen Die botanische Buchillustration. Ihre Geschichte und Bibliographie ist das Werk nicht nachgewiesen. Übrigens war Carl Friedrich von Ledebour ${ }^{\star} 08.07 .1786$ Greifswald, $\dagger$ 04.07.1851 München) nach Abschluss seines Studiums von 1805 bis 1811 Professor der Botanik und Leiter des Botanischen Gartens der Universität Greifswald, bevor er von 1811 bis 1836 als Professor und Direktor des Botanischen Gartens in Dorpat wirkte. In den Jahren von Ledebours Greifswalder Professorentätigkeit weilte Friedrich zweimal bei seinen Verwandten in der Vaterstadt, so im Sommer 1806 und im Frühjahr 1809. Es ist daher sehr wahrscheinlich, dass Ledebour in der kleinen Universitätsstadt zumindest weitläufig mit seinem Landsmann Caspar David Friedrich bekannt war, sodass später über ihn zumindest eine vage Kenntnis der romantischen Kunst C. D. Friedrichs nach Dorpat gelangt sein könnte, von der auch A. M. Hagen Kenntnis bekam. 
Für Prof. Fr. Schmalz' (1781-1847) Werk “Tierveredelungskunde” fertigte er 25 Darstellungen von Tieren $a n^{47}$, die ebenso lithographiert und auf Tafeln veröffentlicht wurden. Hagen fertigte auch für Prof. H. Rathke's (1793-1860) wissenschaftliche Arbeiten Illustrationen in Aquatinta aus dem Gebiet der Physiologie und Anatomie an und machte nach eigenen Angaben auch Illustrationen für Dissertationen. Hagens Illustrationen zeichnen sich durch große Genauigkeit und Deutlichkeit aus, wobei ihre saubere und feste Technik Anerkennung verdient." 48

Bedeutsam ist auch Hagens Beitrag zur Buchillustration, den er z. B. zur Ausstattung der Reise zum Ararat von Friedrich Parrot (1792-1841) geleistet hatte. Im Auftrag der russischen Regierung war Parrot 1829 in den Kaukasus und in das durch den Russisch-Türkischen Krieg gerade unter russische Kontrolle gekommene Armenien gereist. Im Laufe dieser Reise bestieg er in der Suche nach der Arche Noah als erster den Berg Ararat. Für die zweibändige Ausgabe steuerte Hagen einige Aquatinten bei, die er nach Skizzen des Autors gefertigt hatte: "Wenn meine Zeichnungen vom Ararat außer dem Vorzug richtiger Verhältnisse auch noch den einer naturgemäßen, treuen Perspektive haben, so gebührt das Verdienst hiervon Herrn Hagen, welcher mit Benutzung genauer Data über die Entfernung der Gegenstände, sowohl in seiner Handzeichnung als dem von ihm selbst gemachten Kupferstiche, alles und weit mehr leistete als ich nach meinen, in perspektivischer Hinsicht sehr mangelhaften Skizzen erwarten konnte". ${ }^{49}$ Mehrere Sepien und Aquatinten mit Ansichten aus dem Kaukasus bezeugen Hagens große Fähigkeit, ihm unbekannt gebliebene Gegenden selbst nach fremden Vorlagen mit großem Einfühlungsvermögen und in vedutenhafter Präzision zur Darstellung zu bringen (Abb. 21). ${ }^{50}$ Hagen hatte sich für diese Buchillustrationen empfohlen, nachdem er sich seit 1832 durch zahlreiche Landschaften in Neu-Lettland und Estland mit Ansichten von Hapsal (Haapsalu) ${ }^{51}$,

47 Friedrich Schmalz, Thierveredelungskunde (Königsberg: Bornträger, 1832); Friedrich Schmalz, Atlas zu Schmalz Thier-Veredelungskunde in 17 Tafeln (Königsberg: Bornträger, 1832).

48 Tartu Riikliku Kunstimuuseumi almanahh 2 (1967), $70-80$ (in deutscher Übersetzung von Leo von Lingen, Jena, als Manuskript, hier S. 5-6).

49 Friedrich Parrot, Reise zum Ararat, 1. Theil (Berlin: Haude und Spener, 1834), 125.

50 Z. B. August Matthias Hagen, Der Kaukasus mit St. Jakobskirche, 1829, Gouache, 202x277 mm, KM Tartu 358 A. Vgl. auch Krüger, Die Zeichenschule der Universität Dorpat 1803-1891, 25 (Abb. 26). 51 August Matthias Hagen, Hapsal (Haapsalu), Bischofsburg, Aquatinta, 241x330 mm, Universitätsbibliothek Tartu, ÜR 1055. 


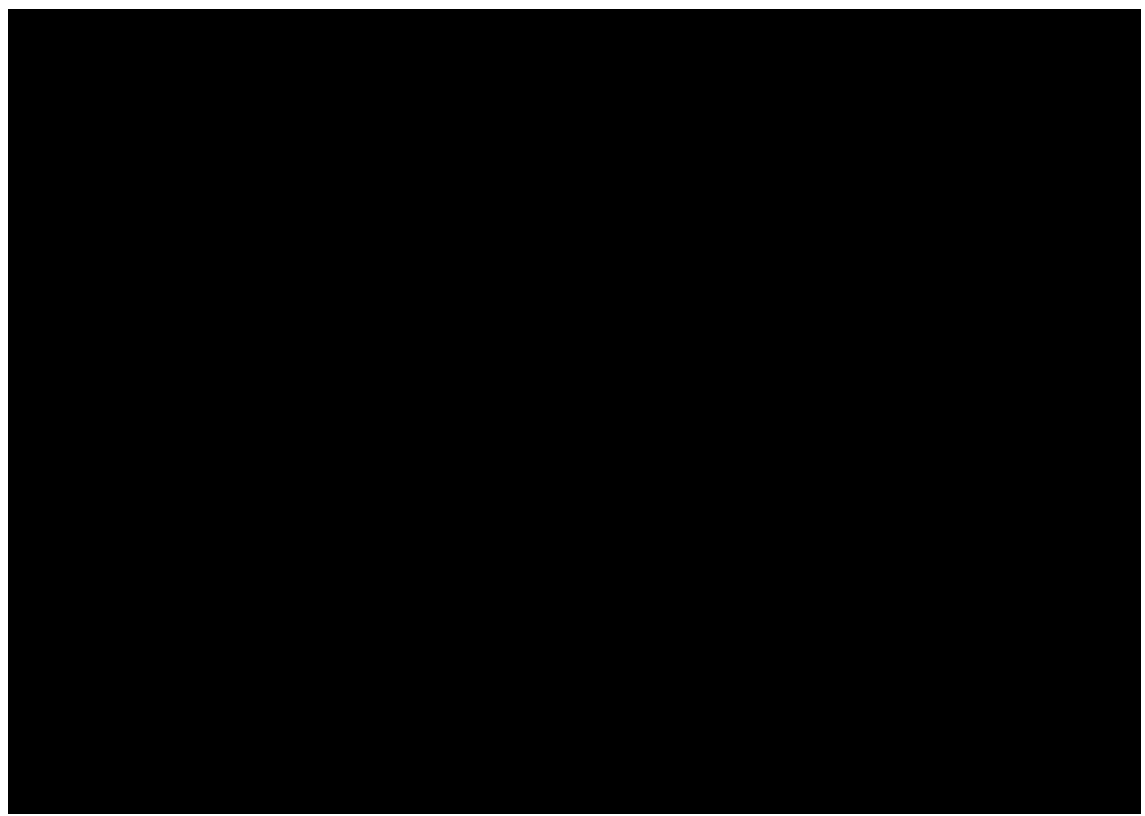

Abb. 21. August Matthias Hagen, Der kleine und der große Ararat von der N. Seite/aus Kanakir bei Erivan in 60 Werst Entfernung, Aquatinta. Fr. Parrot, Reise zum Ararat. Th. 1. Berlin, 1834, S. 159.

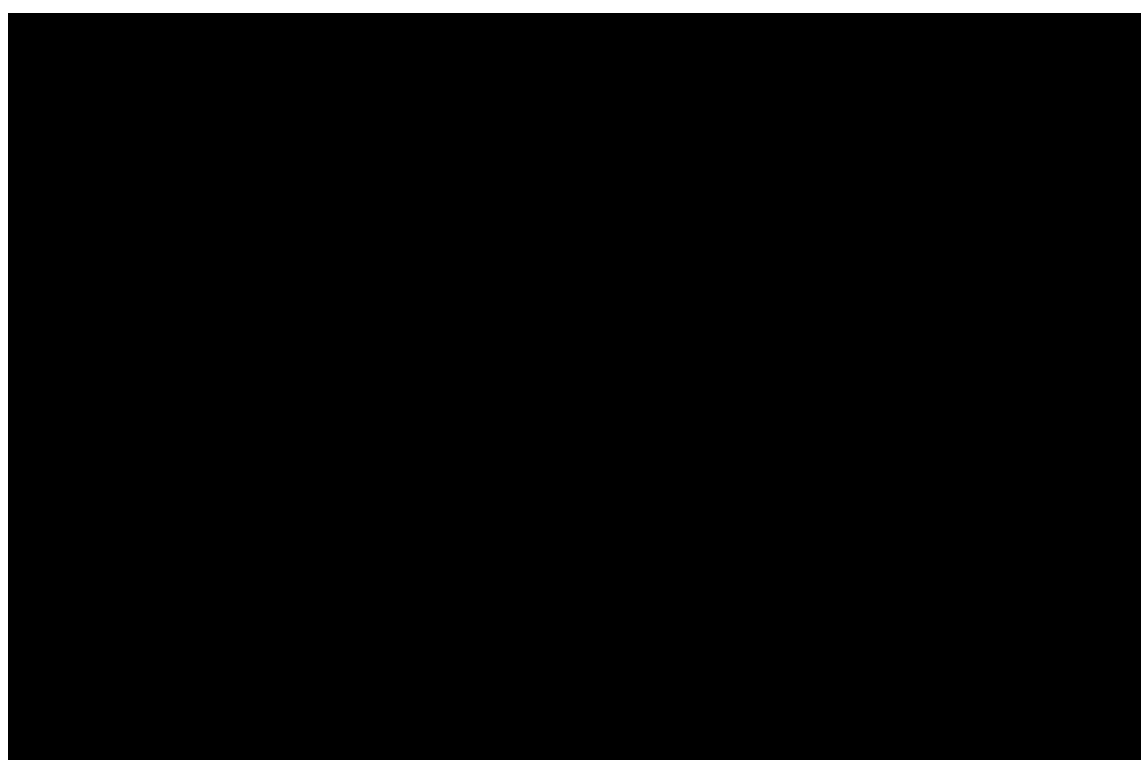

Abb. 22. August Matthias Hagen, Kirche in Karksi/Karkus, Ölgemälde, 1840. Estnisches Kunstmuseum. 
Treiden (Turida) $)^{52}$, Wenden (Cēsis) ${ }^{53}$, Dorpat (Tartu) und Umgebung ${ }^{54}$, aus dem Kreis Wolmar (Valmiera) ${ }^{55}$, von Segewold (Sigulda) ${ }^{56}$, Kokenhusen (Kokenusene/Koknese) ${ }^{57}$, Keila-Fall (Keila-Joa) ${ }^{58}$ und vielen anderen Orten Est- und Livlands mit besonderen Naturschönheiten ${ }^{59}$, Ruinen, Burgen, Schlössern oder sonstigen Sehenswürdigkeiten einen guten Namen in der Heimat gemacht hatte. Dabei malte er nicht nur in Sepiatechnik, sondern begann sich ebenso der Ölmalerei zu widmen, wie es u. a. die beiden Gemälde mit Ansichten der Kirche in Karksi/Karkus (Abb. 22) oder der Ruinen der Burg Karksi/Karkus (Abb. 23) aus dem Estnischen Kunstmuseum in Tallinn zeigen, deren besondere Reize in der Hervorhebung einer idyllisierenden Stimmung liegen, wie sie die Epoche des Biedermeiers so liebte: Natur und Menschenwerk erscheinen hier in harmonischem Einklang zu stehen; das Licht strahlt sonntägliche Ruhe oder friedliche Abendstimmung - selbst bei winterlich klirrender Kälte - aus.

In unterschiedlichen Techniken und stilistischen Ausdrucksformen bewies Hagen seit Beginn der dreißiger Jahre des 19. Jahrhunderts immer wieder, dass er sein künstlerisches Handwerk perfekt beherrschte und in seiner Darstellungsweise ganz auf der Höhe der Zeit stand,

52 August Matthias Hagen, Landschaft von Treiden/Turaida in Livland (Gauja-Tal in Lettland mit dem Turm von Turaida), Sepia, 1832, Staatliches Historisches Museum Estlands, Tallinn (Vgl. Vaga, Kunst Tartus XIX sajandil, Abb. 58).

53 August Matthias Hagen, Landschaft bei Wenden/Cèsis in Lettland mit den Ruinen der ehemaligen Katharinenkapelle, Sepia, 1832, Staatliches Historisches Museum Estland, Tallinn.

54 August Matthias Hagen, Dorpat/Tartu mit Brücke über den Embach (Juni 1832), Sepia, Gouache, 300x390 mm, KM Tartu, 1119B; August Matthias Hagen, Kegelbahn beim Wirtshaus "Zum weißen Ross" (Tamme-Krug) in der Nähe von Dorpat/Tartu, Sepia, 1832, Staatliches Historisches Museum Estlands, Tallinn. Vgl. Vaga, Kunst Tartus XIX sajandil, Abb. 61); August Matthias Hagen, Schloß Ratshof, Sepia, Aquarell, 220x304 mm, KM Tartu, 1120 B; August Matthias Hagen, Ansicht der Stadt Dorpat/Tartu, 1833, Sepia, KM Tartu (Vgl. Vaga, Kunst Tartus XIX sajandil, Abb. 63) u. a. m.

55 August Matthias Hagen, Ruine Rosenbeck im Kreis Wolmar / Valmiera, 1832, Sepia, Tusche 330x423 mm, Estnisches Historisches Museum Tallinn, G 6235.

56 August Matthias Hagen, Landschaft in Lettland mit den Ruinen der Burg Segewold/Sigulda, Sepia, 1833, Staatliches Historisches Museum Estlands, Tallinn (Vgl. Vaga, Kunst Tartus XIX sajandil, Abb. 60). 57 August Matthias Hagen, Ruine Kokenhusen, (Kokenusene/Koknese), Kreis Riga, 14./15. Juli 1833, Sepia 350x425 mm, Estnisches Historisches Museum Tallinn, G 6203 (Vgl. Krüger, Die Zeichenschule der Universität Dorpat 1803-1891, Abb. S. 20); August Matthias Hagen, Kokenhusen, d. 18. Juli 1833, Aquarell, 328x417 mm, Universitätsbibliothek Tartu, ÜR 3669; August Matthias Hagen, Landschaft aus der livländischen Schweiz (Kokenhusen, 19.7.1833), Aquarell, 412x526 mm, Universitätsbibliothek Tartu, ÜR 3668.

58 August Matthias Hagen, Ansicht des Schlosses Keila-Joa (Keila-Fall). 1834, Sepia, Staatliches Historisches Museum Estlands, Tallinn (Vgl. Vaga, Kunst Tartus XIX sajandil, Abb. 64).

59 August Matthias Hagen, Riesensteine am Strand von Tischert (Vgl. Krüger, Die Zeichenschule der Universität Dorpat 1803-1891, 12). August Matthias Hagen, Landschaft mit einer Eiche, 1832, Sepia, Staatliches Historisches Museum Estlands, Tallinn (Vgl. Vaga, Kunst Tartus XIX sajandil, Abb. 62); August Matthias Hagen, Nord-Estland, Strand, 1834, Sepia, Gouache, 313x429 mm, Universitätsbibliothek Tartu, ÜR 4693. 


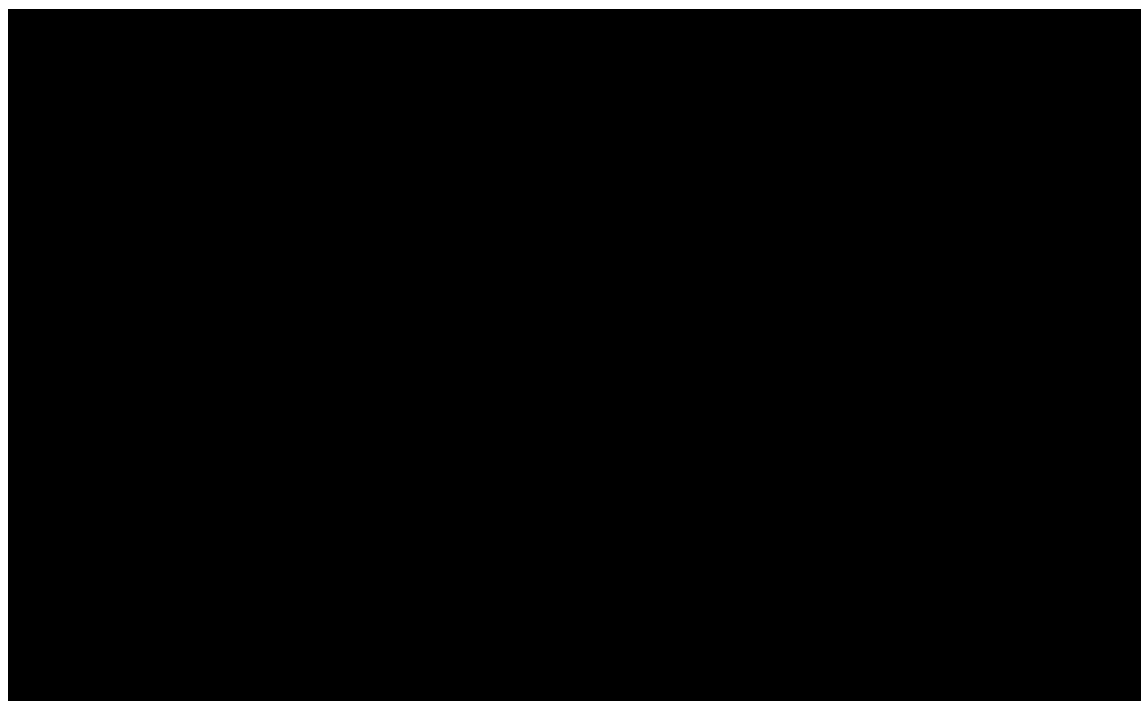

Abb. 23. August Matthias Hagen, Der Ruinen der Burg Karksi/Karkus, Ölgemälde, 1842. Estnisches Kunstmuseum.

ungeachtet dessen, dass sich auch jetzt noch in seinem Schaffen gelegentliche Rückgriffe auf Anregungen auf den empfindsamen Klassizismus in der Art Salomon Geßners und seiner Idyllen finden, mit denen er in Nachfolge von Claude Lorrains (1600-1682) klassischer Landschaftskunst auf Wünsche von Auftraggebern und Kunden einzugehen vermochte. ${ }^{60}$ Vor diesem Hintergrund seines außerordentlichen Leistungsvermögens im Landschaftsfach zu dieser Zeit - immerhin genoss er aufgrund seiner Schulung in der präzisen Wiedergabe wissenschaftlicher Illustrationen zu Werken Dorpater Professoren inzwischen "den Ruf eine[r] der vorzüglichsten einheimischen Landschaftsmaler" ${ }^{\prime \prime 1}$ zu sein - erklärt sich auch die Auftragsvergabe des Zarenhofes zur Fertigung von einer Serie von 29 Gemälden für die er am 24. Juli 1835 von der Kaiserin mit einem Brillantring ausgezeichnet worden sein soll62. “Die Übergabe der Gemälde an die Petersburger Kunstsammlungen hob in Dorpat Hagens

60 Z. B. August Matthias Hagen, Ansicht mit dem Turaida-Turm (Treiden) in Lettland. Öl/Lw., Aufbewahrungsort unbekannt. Vgl. Vaga, Kunst Tartus XIX sajandil, Abb. 69.

61 Sitzungsberichte der gelehrten estnischen Gesellschaft zu Dorpat 1878 (Dorpat: Gelehrte Estnische Gesellschaft zu Dorpat), 203.

62 Vgl. Tartu Riikliku Kunstimuuseumi almanahh 2 (1967), 70-80 (in deutscher Übersetzung von Leo von Lingen, Jena, als Manuskript, hier S. 7) bzw. Asvarishch, German and Austrian Painting. Nineteenth and Twentieth Centuries, 114. 
Ansehen als Künstler und in ihm selbst wurde der Glaube an seine Fähigkeiten vertieft. Deshalb beschloss er, sich bei der Akademie der Künste in Petersburg um die bisher fehlende Qualifikation zu bemühen." ${ }^{\prime \prime 3}$ Nachdem Hagen der Attestationskommission zwei Landschaftsgemälde vorgestellt hatte, die am 26 . September 1837 begutachtet wurden, erhielt er die Genehmigung, sich um den Titel eines Akademiemitgliedes zu bewerben. Dieser günstige Bescheid kam ihm zweifellos zugute, als er sich nach dem am 2. Januar 1838 erfolgten Tod seines Lehrers Carl August Senff um die nun vakant gewordene Stelle des akademischen Zeichenlehrers an der Universität Dorpat bewarb. In Konkurrenz mit drei weiteren Bewerbern wurde Hagen, trotz des noch fehlenden akademischen Titels als Voraussetzung, zum Leiter und Lehrer der Zeichenschule an der Universität Dorpat wohl aufgrund seiner reichen Erfahrungen als Kunstpädagoge gewählt, so dass er am 10. Mai 1838 die neue Position einnehmen durfte, obgleich vorher viele bürokratische Hindernisse zu überwinden waren. Zur Zeit seiner Anstellung hatte inzwischen massiv die Verdrängung des Kupferstichs durch die Lithographie in den künstlerischen Vervielfältigungstechniken eingesetzt, sodass nun Hagen gegenüber seinem Vorgänger das Schwergewicht der Ausbildung stärker auf das Zeichnen statt auf die Reproduktionstechniken richtete.

\section{HAGEN ALS LEITER DER UNIVERSITÄTSZEICHENSCHULE DORPAT UND DIE REALISTISCHE LANDSCHAFTSMALEREI}

Außerhalb des Universitätsbetriebs betätigte sich Hagen ebenfalls als Pädagoge. Davon profitierten vor allem seine beiden Kinder, die Tochter Julie und der Sohn Alexander. Beide absolvierten nach ihrer Grundausbildung durch den Vater eine professionelle Schulung: Julie setzte ihre Studien in Dresden, München und Rom fort, Alexander erhielt an der Münchner Akademie seinen pädagogischen Schliff, bevor er nach seinen Reisen nach Rom (1852-1856) und Paris (1856-1857) Europa verließ. Zunächst folgte er dem bayerischen Gesandten Wegner auf eine Forschungsexpedition (1857-1859) durch Südamerika, lebte abwechselnd in Deutschland und Paris, war danach in Peru längere Zeit als Porträtist

63 Tartu Riikliku Kunstimuuseumi almanahh 2 (1967), 70-80 (in deutscher Übersetzung von Leo von Lingen, Jena, als Manuskript, hier S. 78). 


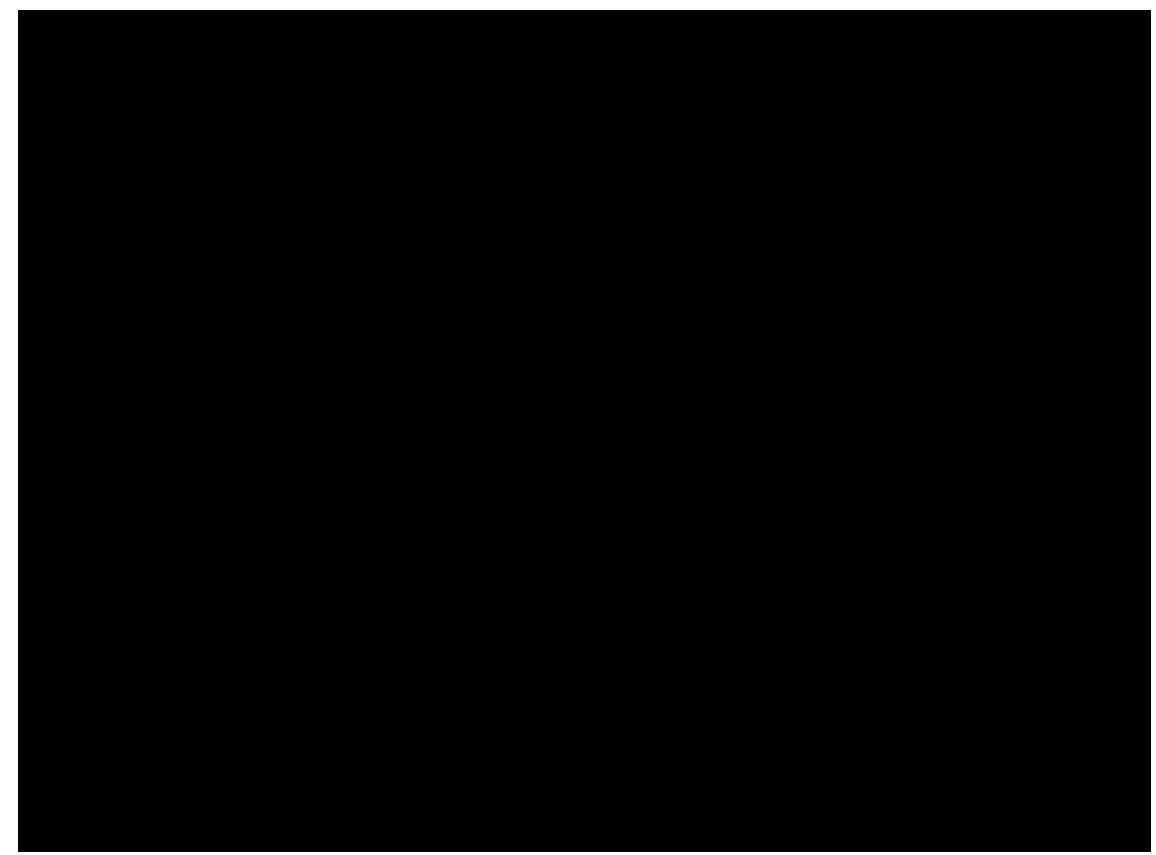

Abb. 24. August Matthias Hagen, Alte Linden von Tamme-Krug bei Tartu, Ölgemälde, 1838. Estnisches Kunstmuseum.

tätig und besuchte 1868 noch einmal die Familie im Baltikum, bevor er sich 1869 erneut nach Südamerika einschiffte und noch im selben Jahr dort an den Pocken starb.

Ungeachtet seiner Verpflichtungen als Universitätszeichenlehrer ${ }^{64}$ blieben Hagen genügend Freiräume, um sich weiterhin seiner Kunst widmen zu können. Das Gemälde Alte Linden von Tamme-Krug bei Tartu (Abb. 24) ${ }^{65}$ aus dem Jahre 1838 vermittelt uns eine Vorstellung davon, wie fortan für den Künstler die Position eines konsequenten Realismus bestimmend wurde, der sich zum Teil an den Vorgaben der holländischen Schule des Meindert Hobbema (1638-1709) zu orientieren scheint. Nach den Erfahrungen, die er mit der weltanschaulich-wertenden Stimmungskunst der Romantik sowie mit dem Erdlebenbild zur

64 Vgl. Ibidem, 70-80 (in deutscher Übersetzung von Leo von Lingen, Jena, als Manuskript, hier S. 9-15); Krüger, Die Zeichenschule der Universität Dorpat 1803-1891, 10-11.

65 Das Motiv des Tamme-Krugs scheint Hagen in seiner Laufbahn häufig beschäftigt zu haben, wie eine Goauche vom 7. September 1851 im Kunstmuseum Tartu zeigt. Vgl. Krüger, Die Zeichenschule der Universität Dorpat 1803-1891, 17. 
Offenbarung der Naturgeheimnisse gemacht hatte, und nachdem er auch die poetische Bildsprache des empfindsamen Klassizismus mit seinen idyllischen Harmonien hinter sich gelassen hatte, richtete sich jetzt sein künstlerisches Augenmerk ganz auf die "schlagende Naturwahrheit" wie sie Ludwig Richter im Schaffen Johan Clausen Dahls ausgemacht hatte. Selbst wenn romantische Relikte wie das Abbild eines abgestorbenen Baumes als Repoussoir-Motiv aus dem Kompositionskanon der klassischen Landschaft noch nachwirken, überwiegt doch die nüchterne Wiedergabe eines schönen Fleckens heimatlicher baltischer Erde, über deren tiefen Horizont sich der weite Himmel eines kühlen Sommertages spannt, um damit der idyllisierenden Wirkung der ungetrübten Sonntagsatmosphäre des biedermeierlichen Realismus entgegenzuwirken. Der Landschaftsausschnitt, den uns der Künstler vorstellt, will weder Lieblichkeit noch Todessehnsucht zur Schau stellen; ebenso wenig will er erhabene Größe noch gemütliche Schönheit zeigen. Hagen bemüht sich lediglich darum, den Ausblick auf die eigentlich unspektakuläre Natur so wiederzugeben, wie sie ihm erscheint. Damit bewegt er sich tendenziell auf eine künstlerische Haltung zu, wie sie die französischen Realisten der Schule von Barbizon mit ihrer Freilichtmalerei etwa gleichzeitig verfochten, ohne dass Hagen von deren Schaffensweise wusste. Ihn verband mit diesen Künstlern das gemeinsame Vorbild der holländischen Landschaftskunst von Meindert Hobbema und Jacob van Ruisdael als Quelle der Inspiration, die ihn zu ähnlichen künstlerischen Ergebnissen führte, wie sie die Franzosen in ihrer "Paysage intime" entwickelt hatten. Allerdings ähneln seine Werke nur in ihrem unspektakulären, ländlichen Motiv im intimen Naturausschnitt und unter weitgehendem Verzicht auf Figurenstaffage den vergleichbaren Bestrebungen der Franzosen; der lichtdurchfluteten Freilichtmalerei, die dann später zur Herausformung des Impressionismus führte, öffnete Hagen mit seinen Landschaftsdarstellungen freilich noch nicht den Weg. ${ }^{66}$

66 Vgl. John Sillevis, Hans Kraan, De School van Barbizon. Franse meesters van de 19de eeuw (Den Haag: Haags Gemeentemuseum, 1985). 
HAGENS ALTERSWERK ZWISCHEN SCHAFFENSKRISE UND LETZTER PRODUKTIVER HOCHPHASE WÄHREND SEINES RÖMISCHEN AUFENTHALTS

Jetzt, nach der Berufung zum Universitätszeichenlehrer, zeigte sich Hagens realistische Bildsprache mehr und mehr gefestigt und er hatte die ihm eigene Ausdrucksweise gefunden. Weiterhin bildete die Darstellung der heimischen livländischen Landschaft das Hauptrepertoire seiner Landschaftsgemälde, -aquarelle, -gouachen, -sepien und -zeichnungen, wobei sich gleichermaßen reine Naturschilderungen neben Bildern finden, die mit Menschen und Tieren staffiert sind. Dabei gehörte die heute südestnische Region um Viljandi (ehemals Fellin) mit der Burgruine Helme (Helmet) (Abb. 25) sowie das heute nordlettische Gebiet um Wenden (Cēsis) ${ }^{67}$ und Treiden (Tureida) zu den bevorzugten Zielen seiner damaligen Studienreisen. Seit Mitte der vierziger Jahre machte sich eine rapide Verschlechterung seines Gesundheitszustandes bemerkbar ${ }^{68}$, sodass er sich sogar in seiner Lehrfunktion von seinem Schüler und späteren Nachfolger im Amte Woldemar Friedrich Krüger (1807-1893) hatte vertreten lassen müssen, um 1846 gemeinsam mit der Tochter Julie eine Reise nach Deutschland zur Kur unternehmen zu können. Bei dieser Gelegenheit brachte Hagen Julie zum Malunterricht nach Dresden. Unter diesen ungünstigen Bedingungen beschränkte sich nach seiner Rückkehr aus Deutschland der Radius seiner Studienreisen zunächst auf das engere Umfeld Dorpats (Abb. 25/26) ${ }^{69}$ und generell ließ seine Arbeitsproduktivität nach, obgleich er bis in die sechziger Jahre hinein weiter schöpferisch tätig blieb. In den Jahren 1850 und 1851 beteiligte er sich sogar zusammen mit seiner Tochter und dem Augsburger Maler Moritz Rugendas (1802-1858) an den in Dorpat durchgeführten Kunstausstellungen, doch sah er sich wegen zunehmender gesundheit-

67 Z. B. August Matthias Hagen, Landschaft mit Ruinen (Cèsis/Wenden), den 14. Juni 1843, Sepia, Gouache, Universitätsbibliothek Tartu, ÜR 3672, vgl. 200 Jahre Kunstlehre in Estland. Zeichenschule der Universität Tartu 1803-1893, hrsg. Inge Kukk, Epp Preem (Tartu: Tartu Ülikooli Kunstimuuseum, Tartu Kunstimuuseum, 2002), 53.

68 Vor allem Hagens Sehvermögen hatte wesentlich nachgelassen, nachdem er bereits schon seit frühester Jugend auf seinem linken Auge erblindet war, drohte ihm nun auch der Verlust des rechten Augenlichtes.

69 Vgl. August Matthias Hagen, Ansicht des Dombergs in Tartu mit der Sternwarte, 1850, Bleistift und Sepia, KM Tartu. Vgl. Vaga, Kunst Tartus XIX sajandil, Abb. 74; August Matthias Hagen, Krug zum weißen Roß bei Dorpat (Tamme-Krug), 7. September 1851, Bleistift, Sepia, Gouache 220x310 mm, KM Tartu, 1121 B. Vgl. Krüger, Die Zeichenschule der Universität Dorpat 1803-1891, 17. 


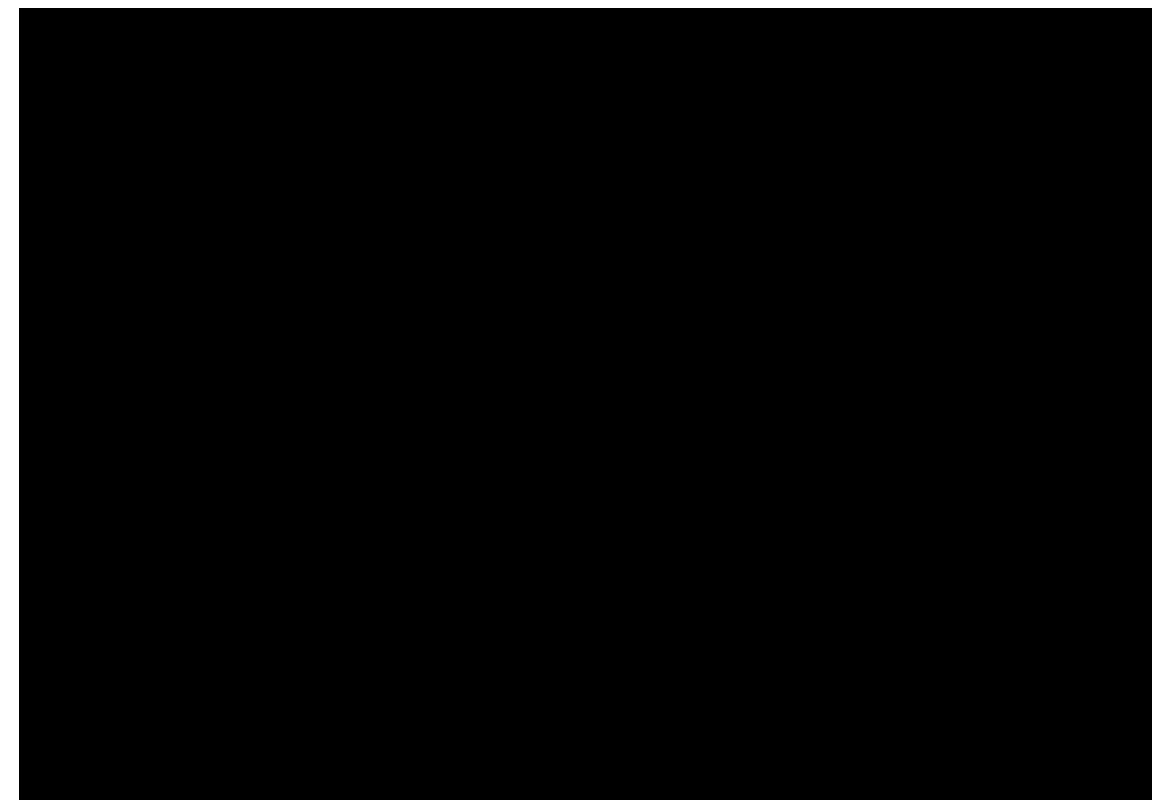

Abb. 25. August Matthias Hagen, Ruine Helme, Kreis Fellin, Sepia und Gouache, 1842. Estnisches Historisches Museum.

licher Probleme veranlasst, nach 131/2-jähriger Dienstzeit schließlich am 30.11.1851 sein Gesuch um Pensionierung einzureichen, wobei ihm bis zu seinem Tod sein volles Gehalt weitergezahlt wurde.

Im darauffolgenden Jahr verließ Hagen Dorpat noch einmal, um nach München zu reisen, wo sein Sohn Alexander an der Akademie sein Kunststudium absolvierte, und nach Rom, wo seine Tochter Julie mit Hilfe eines Stipendiums der Petersburger Akademie bei dem Maler August Riedel (1799-1883) ihre Studien fortgesetzt hatte. In dieser Phase anregender Kontakte mit Kollegen setzte bei A. M. Hagen letztmalig eine intensive Schaffenswelle ein, in der er zahlreiche Bleistiftskizzen und Zeichnungen in verschiedenen Techniken schuf, die zum Teil im familiären Nachlass erhalten sind. Sie zeigen Stationen seiner Reise durch Deutschland ${ }^{70}$ bis nach Italien - vor allem Rom (Abb. 12, 13) und

70 Z. B. August Matthias Hagen, Landschaft mit Häusern und Kuhherde, 30. Juli 1852 (Bad Elster), Bleistift, Sepia, 265x210 mm, EKM G 200, vgl. Krüger, Die Zeichenschule der Universität Dorpat 1803-1891, 29. 


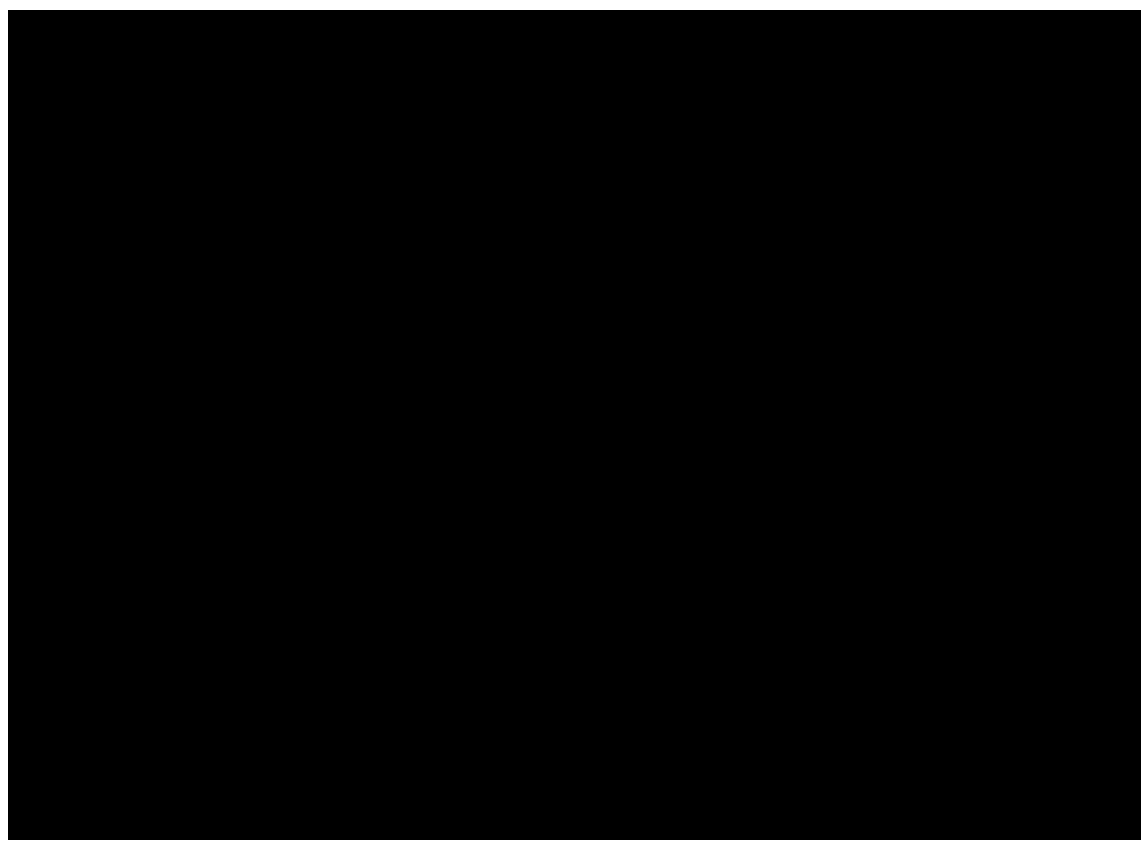

Abb. 26. August Matthias Hagen, Ansicht von Dorpat mit der Marienkirche, Bleistift und Sepia, 1851. Tartuer Kunstmuseum.

Neapel $^{71}$ - wohin er gemeinsam mit der Tochter fuhr, einschließlich von der 1853 erfolgten Rückreise über Tirol und Salzburg. ${ }^{72}$ Hagens letzte gröBere Studienreise führte ihn 1855 noch einmal nach Finnland, als deren Ergebnisse u. a. eine Ansicht von einem kleinen See auf der Insel Hochland (Abb. 27) mit einer Rückenfigur als romantischem Identifikationsmodell und eine Ansicht vom Oberen See in Tammerfors ${ }^{73}$ entstanden. Hier besann er sich ein letztes Mal auf die in seinem Schaffen bedeutsamste

71 Z. B. August Matthias Hagen, Blick auf Rom mit Vatikan, 21. November 1852, Sepia, 341x250 mm, Privatbesitz, vgl. Krüger, Die Zeichenschule der Universität Dorpat 1803-1891, 29, Abb. S. 30; August Matthias Hagen, Blick auf den Vesuv 4.12.52, Biester und Federzeichnung, 305x401 mm, Privatbesitz, vgl. Krüger, Die Zeichenschule der Universität Dorpat 1803-1891, 29, Abb. S. 32; August Matthias Hagen, Ansicht von Rom, 1853, Bleistift, Sepia, Aufbewahrungsort unbekannt, vgl. Vaga, Kunst Tartus XIX sajandil, Abb. 76; August Matthias Hagen, Italienische Landschaft, 1853, Bleistift, Sepia, Aufbewahrungsort unbekannt, vgl. Vaga, Kunst Tartus XIX sajandil, Abb. 77.

72 Z. B. August Matthias Hagen, Landschaft bei Salzburg, 1853, Bleistift, Sepia, Aufbewahrungsort unbekannt, vgl. Vaga, Kunst Tartus XIX sajandil, Abb. 78; August Matthias Hagen, Tirol (Felsschlucht mit Wasserfall), 1853. Sepia, Gouache, 306×293 mm, KM Tartu, vgl. Vaga, Kunst Tartus XIX sajandil, Abb. 79, bzw. Hagen, Alpenreise. Tagebücher, 115, Abb. 18.

73 August Matthias Hagen, Der Obere See in Tammerfors (Finnland), September 1855, Sepia, 283x454 mm, Privatbesitz, vgl. Krüger, Die Zeichenschule der Universität Dorpat 1803-1891, 29. 


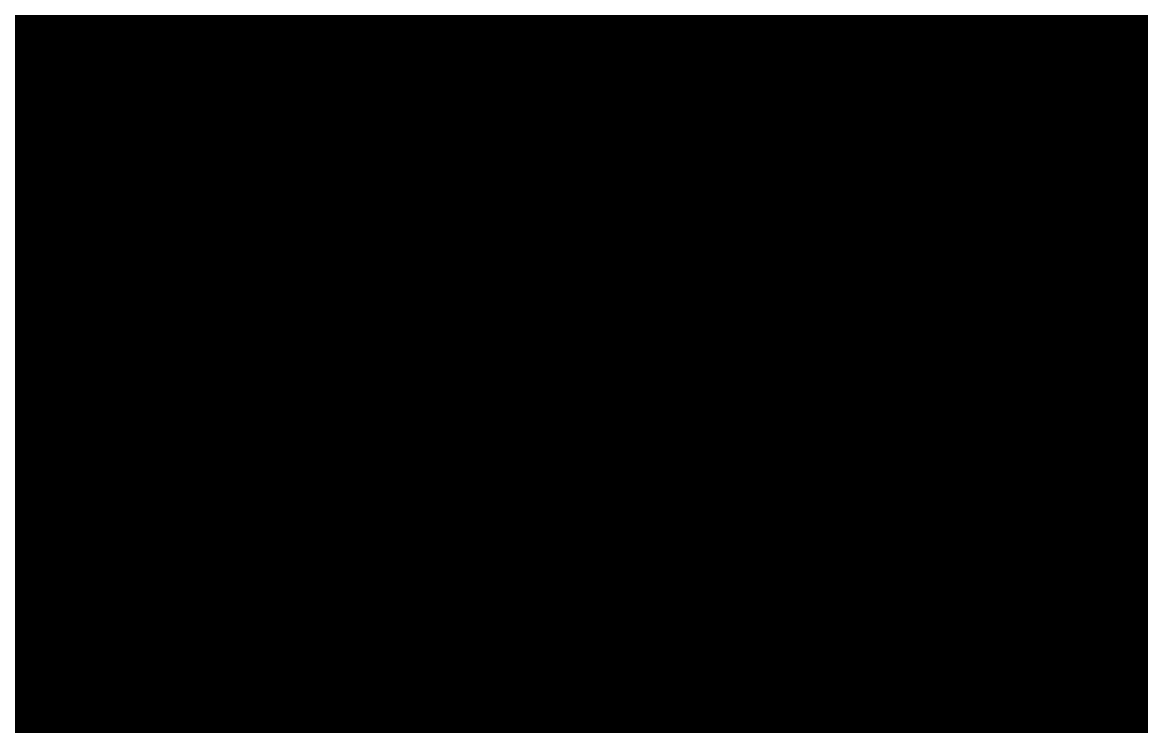

Abb. 27. August Matthias Hagen, Ein kleiner See auf der Insel Hogland, Sepia, 1855. Privatbesitz.

Phase romantischer Landschaftskunst in der Mitte der dreißiger Jahre des 19. Jahrhunderts und vermittelt bei allem Realismus im Detail eine stimmungsvolle Sicht, deren philosophische Wurzeln in einer ganz auf Transzendenz gerichteten Weltbetrachtung liegt, mit der er wehmutsvoll Abschied von seiner aktiven Künstlerlaufbahn zu nehmen scheint. Unwillkürlich fühlt man sich beim Betrachten dieses Blattes an die biblische Erzählung des Moses erinnert, der kurz vor seinem Tod noch das Gelobte Land sehen kann, ohne es betreten zu dürfen. ${ }^{74}$

In den 1860er Jahren verlor Hagen sein Sehvermögen gänzlich. Als eines der letzten von ihm gemalten Bilder schuf er vermutlich eine Italienische Landschaft (Abb. 28) ${ }^{75}$, eine idyllisierende Reminiszenz an die schönen Tage des gemeinsamen Aufenthalts mit der Tochter im Lande der Künste und schönen Natur. Bewusst greift er in diesem Phantasiestück, mit dem er seinen Erinnerungen nachträumt, noch einmal auf die Erfahrungen der Landschaftskunst des Klassizismus zu-

74 Vgl. Genesis 5, Kapitel 32, Verse 48-52.

75 Bei Vaga, Kunst Tartus XIX sajandil, Abb. 57, ist das Bild 1830 datiert, während es bei 200 Jahre Kunstlehre in Estland. Zeichenschule der Universität Tartu 1803-1893, 52, Abb. 55, erst 1860 datiert ist. Da ich das Bild nicht selbst gesehen habe, muss offen bleiben, ob das Werk noch Hagens früher Schaffensphase zuzuordnen ist, was durchaus passen würde, oder ob es im Spätwerk als eine Reminiszenz an die Jugendzeit zu werten ist. 


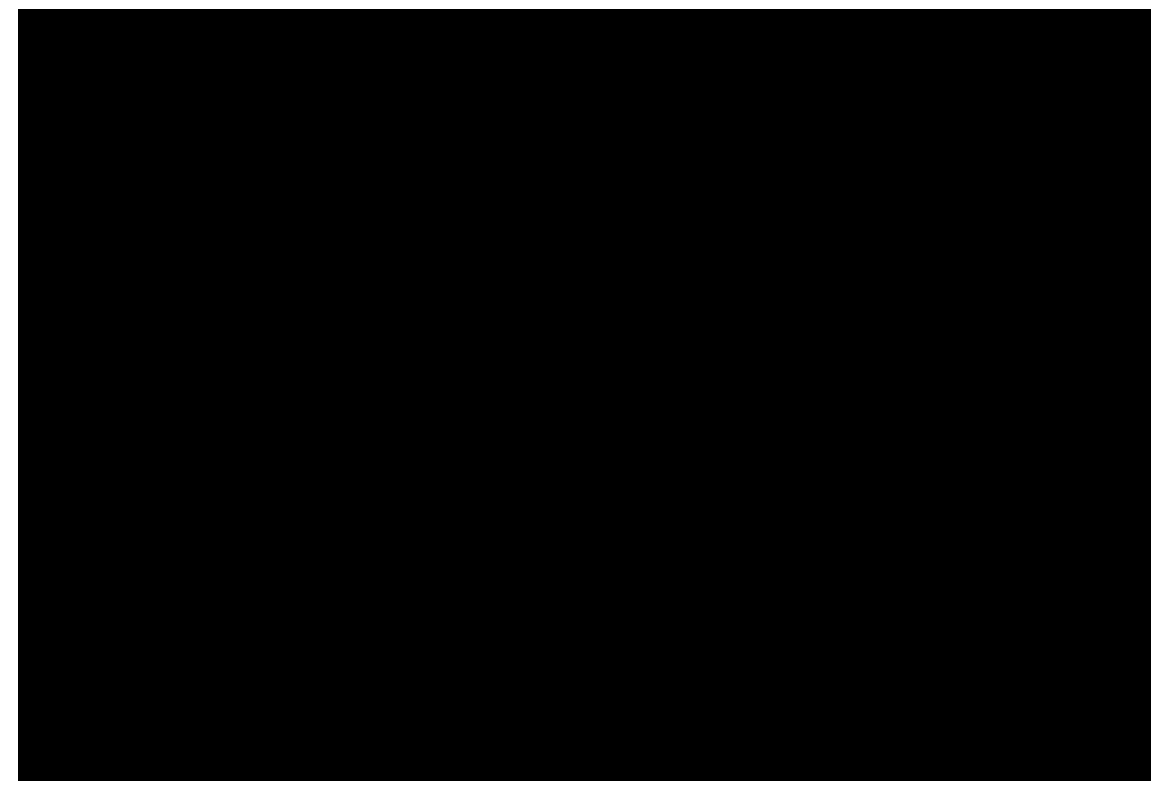

Abb. 28. August Matthias Hagen, Landschaft in Italien, Ölgemälde, 1860. Tartuer Kunstmuseum.

rück, bei der nicht unbedingt die visuelle Wahrheit, sondern die ideale Schönheit einer Naturszene im Vordergrund steht. Zur Formulierung eines Künstlertraums war diese Konzeption nach wie vor bestens geeignet!

Hagen starb erst viele Jahre später im hochbetagten Alter von 84 Jahren am 20. November 1878. Er fand seine letzte Ruhestätte auf dem Johannesfriedhof von Tartu. Den Anschluss an die Landschaftskunst der Avantgarde, die inzwischen von den Impressionisten geführt wurde, hatte er nicht mehr gefunden. In seiner Kunst blieb er den alten Prinzipien einer realistischen Landschaftsmalerei treu, die handwerklich solide und mit poetischem Gespür die Schönheiten vor allem im ländlichen Raum Estlands zu entdecken suchte, sich aber nicht um eine revolutionär-neue Sicht auf die Wirklichkeit bemühte. Provinzelle Abgeschiedenheit hatte ihn zu biedermeierlicher Selbstgenügsamkeit geführt, die nicht mehr die Kraft besaß, die alten Traditionen, die er aus dem akademischen Klassizismus fortsetzte, über Bord zu werfen und sie durch neue Darstellungsideale zu ersetzen. Diese Entwicklung wurde in den großen Kunstzentren Europas, vor allem in Paris, aber auch in München und Berlin, vorangetrieben. Hagens Kunst in Dorpat beschränk- 
te sich hingegen auf die Solidität des jahrzehntelang Bewährten, das den großen Strömungen der modernen Kunst nur mit Zögern folgte. Dieser Umstand erklärt auch, weshalb Hagens Kunst über den engeren lokalen Kreis der einst russischen Ostseeprovinzen kaum hinausgewirkt hat.

\section{ZUSAMMENFASSUNG}

Bislang war das Kunstschaffen von August Matthias Hagen, des ehemaligen Zeichenmeisters der Universität Dorpat, über die Grenzen Estlands hinaus kaum bekannt. So brachte die Begegnung mit Werken seiner Kunst in den Ausstellungen von Hamburg 2006 und in Amsterdam 2008 eine Neubewertung seiner Kunst, da vor allem in den Zeichnungen und Gemälden, die er in der Mitte der 1830er Jahre von Südfinnland schuf, eine große Affinität mit der Ästhetik und Geisteshaltung der Dresdner Romantiker aus dem Umfeld von Caspar David Friedrich festzustellen ist. Der Aufsatz stellt nicht allein die innere Verwandtschaft des Kunstschaffens von A. M. Hagen in seiner künstlerischen Hochphase mit der Landschaftsmalerei von C. D. Friedrich, Carl Gustav Carus und Johan Christian Clausen Dahl heraus, sondern sucht zugleich die Wege aufzuzeigen, wie die romantische Spiritualität der Dresdner Romantiker vom Beginn des 19. Jahrhunderts zu A. M. Hagen gelangte und dann dessen Kunstschaffen für längere Zeit stark beeinflusste. Zweifellos stellte Wassilij Andrewitsch Shukowski, der russische Dichter, Erzieher des Zarewitsch und zeitweilige Kommilitone Hagens an der Dorpater Universitätszeichenschule, das Hauptbindeglied dar, das zwischen A. M. Hagen und der Dresdner Kunstszene vermittelte. Über Shukowski und über den Dorpater Prof. Johann Christian Moyer lernte Hagen nicht nur einzelne Werke Friedrichs im Original kennen, sondern auch die theoretischen Grundlagen des romantischen Erdlebenbildes, wie es Carl Gustav Carus in seinen Zehn Briefe über Landschaftsmalerei formuliert hatte und die 1835 bereits in einer zweiten Ausgabe erschienen. Vor allem reflektieren die im Auftrag des Zaren entstandenen Zeichnungen und Gemälde mit Ansichten der von Russland neu gewonnenen Teile Finnlands - besonders die Darstellungen von der Insel Hogland - Hagens intensive Auseinandersetzung mit Carus' Theorie der romantischen Landschaftsmalerei. Doch bald schon sollte sich A. M. Hagen von diesen romantischen Positionen philosophischer Sehnsuchts- 
und Erlösungsvorstellungen wieder lösen und diese durch eine der poetischen Wirklichkeitssicht verpflichteten Auffassung zu ersetzen, die deutlich die Merkmale von J. C. C. Dahls romantischen Realismus trägt. In der Nachfolge dieses neuen künstlerischen Leitsterns entwickelte sich Hagens Kunst allmählich in Richtung einer topographisch getreuen Vedutenmalerei, die einen nüchternen Realismus im Geist des Biedermeiers verfocht. Damit verlagerte Hagen den Schwerpunkt seines Schaffens von der romantischen Landschaftsmalerei, die als Stimmungs- und Bedeutungsträger fungierte, hin zu einer sonntäglichen Idyllisierung der landschaftlichen Wirklichkeit. Ein Rückblick auf Hagens Frühwerk vor seiner Begegnung mit der romantischen Landschaftskunst Dresdens und ein Ausblick auf die Schaffenszeit nach der Rückkehr von der Studienreise nach Deutschland, Österreich und der Schweiz, die Hagen für die Aufnahme neuer künstlerischer Tendenzen sensibilisiert hatte, runden den Überblick über das künstlerische Wirken dieses deutschbaltischen Landschaftsmaler ab. Unter den Bedingungen einer von den deutschen Quellen weitgehend abgeschnittenen Position in der fernen Ostseeprovinz Russlands musste sich Hagen in erster Linie den Erfordernissen des Universitätsbetriebs stellen, der vom akademischen Zeichenmeister vor allem handwerkliche Solidität und nüchterne Beobachtungsgabe forderte, nicht aber spirituellen Tiefgang seiner malerischen Schöpfungen. Diese provinzielle Abgeschiedenheit von den deutschen und auch russischen Kunstzentren bewirkte, dass sich in Hagens Spätwerk eine Tendenz zu unspektakulärer Selbstgenügsamkeit abzeichnet, die sich nicht mehr um Anschluss an avantgardistische Trends bemüht. 
Gerd-Helge Vogel: August Matthias Hagen (1794-1878)

- Baltic German Landscape Painting Between Romantic Beginnings and Provincial Self-Sufficiency

Keywords: August Matthias Hagen; Baltendeutsche Landschaftsmalerei; Romantik; Biedermeier; Zeichenschule DORPAT

SUMMARY:

The art of August Matthias Hagen (1794-1878), once a drawing instructor at Tartu University, was previously almost unknown beyond the borders of Estonia. Awareness of his works came about thanks to the exhibitions in Hamburg (2006) and in Amsterdam (2008), which also brought with them an opportunity for a new assessment of his art. It became evident from the drawings and paintings shown in these galleries that the work he created in the mid 1830's - depicting landscape views of Southern Finland - reveal a great affinity with the aesthetics and spirit of Dresden Romanticism from the circle of Caspar David Friedrich. This essay not only focuses on the debt Hagen's mature work owes to painters like C. D. Friedrich, Carl Gustav Carus, and Johan Christian Clausen Dahl, but it also intends to show how the Romantic spirit of such Dresden artists from the early $19^{\text {th }}$ century came, at least for a certain period of time, to influence A. M. Hagen's art. Without a doubt, Wassilij Andrewitsch Shukowski - a poet, the Russian Zarewich's personal tutor, and Hagen's fellow student at the Drawing School of Tartu University - was the primary connection between A. M. Hagen and Dresden's art milieu. Hagen not only became acquainted with individual works done by Friedrich via Shukowski, but also through the painting collection of Tartu Professor Johann Christian Moyer and from the theoretical fundaments of the Romantic Erdlebenbild - a concept included in Carl Gustav Carus' treatise: Ten Letters about Landscape Painting, (second edition 1835). The drawings and paintings commissioned by the Czar reflect Hagen's intense studies of Carus' theory of Romantic landscape painting, particularly in those works showing views of Finland - like the island of Hogland, territory which had been recently acquired by the Russian Empire. Yet A. M. Hagen soon left behind these Romantic, philosophical ideals involving yearning and redemption. He replaced them with a concept associated with a poetic view of reality clearly embodying J. C. C. Dahl's Romantic Realism. Thus, Hagen's art gradually evolved 
into a quite painstaking, topographically exact rendering of landscapes (vedute) adapted from Dahl's conception of Romantic Realism. But unlike Dahl's poetic vision, Hagen practised a more sober realism fully within the Biedermeier spirit. In this way Hagen changed his orientation from Romantic landscape painting conveying mood and meaning towards an idyllic Biedermeier landscape containing an atmosphere of essentially "idealized reality". This article dealing with the artistic production of the Baltic-German landscape painter August Matthias Hagen includes two aspects of his career: a look back into his early work dating from before his confrontation with Dresden Romantic landscape painting and an overview of his later period - occurring after his return from a study trip to Germany, Austria, and Switzerland - a time when he was then more sensitized to newer tendencies in Romantic art. However, in Tartu, Hagen was essentially responsible for fulfilling the university's curriculum requirements expected from its drawing master: to primarily convey a solid sense of draftsmanship and nurture a sober talent for observation. In addition, because Hagen was isolated from his previous German sources - due to the geographically remote location in the Russian Baltic province - his late landscape paintings lacked a true spiritual profundity. This provincial seclusion from German and Russian art centers caused Hagen's later work to be characterized by a tendency to unspectacular self-sufficiency which made no real effort to maintain connections with newer developments in the more modern, avant-garde trends that subsequently occurred in European art.

CV:

Gerd-Helge Vogel (geb. 1951) ist Dozent für Kunstgeschichte und wissenschaftliche Illustration sowie Projektleiter an der Zürcher Hochschule der Künste und an der Ernst-Moritz-Arndt-Universität Greifswald. 1999 und 2002 Gastdozent des DAAD an der Estnischen Kunstakademie Tallinn. Organisator zahlreicher Romantikkonferenzen und Kurator vieler Ausstellungen im In- und Ausland. Umfangreiche kunsthistorische Publikationstätigkeit über Kunst der Aufklärung und der Romantik, über Gartenkunst, über wissenschaftliche Illustrationen sowie über Plakatkunst. Als letztes erschienen: Pflanzen, Blüten, Früchte. Botanische Illustrationen, Berlin 2014; Aufklärung in Barth, Kiel 2014; Joseph Mattersberger - ein klassizistischer Bildhauer im Dienste der Grafen von Einsiedel, Berlin 2015. 